\title{
Bacia de Santos no Brasil: geologia, exploração e produção de petróleo e gás natural
}

\author{
Leonardo Silveira de Souza ${ }^{1 *}$; Geraldo Norberto Chaves Sgarbi ${ }^{2}$
}

DOI: http://dx.doi.org/10.18273/revbol.v41n1-2019009@_ @

Forma de citar: Souza, L.S., y Sgarbi, G.N.C. (2019). Bacia de Santos no Brasil: geologia, exploração e produção de petróleo e gás natural. Boletín de Geología, 41(1), 175-195. DOI: 10.18273/revbol.v41n1-2019009

\section{RESUMO}

No presente artigo, a partir da revisão bibliográfica e da análise de dados secundários, analisamos as características geológicas da Bacia de Santos, a evolução da exploração e produção de hidrocarbonetos, nos reservatórios do Pós-sal e Pré-sal, que somada à produção da Bacia de Campos, respondem atualmente por $89 \%$ da produção nacional de petróleo e gás natural. As características positivas dos reservatórios de petróleo e gás natural do Présal (volume potencial das reservas, alta produtividade, qualidade do óleo, baixo risco exploratório e de produção) geraram três consequências: a redução do custo de produção, em um momento que o mercado internacional apresenta baixa cotação do barril de petróleo; a atração dos interesses das companhias internacionais e dos seus países de origem em acessarem as reservas do Pré-sal; a Bacia de Santos tornou-se a maior produtora de hidrocarbonetos do Brasil.

Palavras-chave: Bacia de Santos; Petrobras; Exploração de Hidrocarbonetos; Pré-sal brasileiro; Produção de Hidrocarbonetos; Companhias Internacionais do petróleo.

\section{The Santos Basin in Brazil: geology, exploration and production of oil and natural gas}

\begin{abstract}
In this paper, from the bibliographic review and the analysis of secondary data, we analyze the geological characteristics of the Santos Basin, the evolution of the hydrocarbon exploration and production specially, from the Post-salt and Pre-salt reservoirs, that together with the Campos Basin production, currently account for $89 \%$ of the national oil and natural gas production. The positive characteristics of the Pre-salt oil and natural gas reservoirs (potential volume of reserves, high productivity, oil quality, low exploration and production risk) generated three consequences: reducing the cost of production in the same time, low oil crude prices in the international market; interests of international companies and their home countries to access the Pre-salt reserves; the Santos Basin became the largest hydrocarbon producer in Brazil.
\end{abstract}

Keywords: Santos Basin; Petrobras; Hydrocarbons Exploration; Brazilian Pre-salt; Hydrocarbons Production; International Oil Companies.

\footnotetext{
${ }^{1}$ Programa de Pós Graduação em Geologia, Instituto de Geociências, Universidade Federal de Minas Gerais, Belo Horizonte, Brasil. (*) leosilveira.cat@gmail.com

${ }^{2}$ Departamento de Geologia, Instituto de Geociências, Universidade Federal de Minas Gerais, Belo Horizonte, Brasil. gncsgarbi@gmail.com
} 


\section{Cuenca de Santos en Brasil: geología, exploración y producción de petróleo y gas natural}

\section{RESUMEN}

En el presente artículo, a partir de la revisión bibliográfica y del análisis de datos secundarios, analizamos las características geológicas de la Cuenca de Santos, la evolución de la explotación y producción de hidrocarburos, en los depósitos del Post-sal y Pre-sal, que sumada a la producción de la Cuenca de Campos, responden actualmente por el 89\% de la producción nacional de petróleo y gas natural. Las características positivas de los depósitos de petróleo y gas natural del pre-sal (volumen potencial de las reservas, alta productividad, calidad del aceite, bajo riesgo exploratorio y de producción) generaron tres consecuencias: la reducción del costo de producción en un momento que el mercado internacional presenta baja cotización del barril de petróleo; la atracción de los intereses de las compañías internacionales y de sus países de origen en acceder a las reservas del pre-sal; la Cuenca de Santos se convirtió en la mayor productora de hidrocarburos de Brasil.

Palabras clave: Cuenca de Santos; Petrobras; Exploración de hidrocarburos; Pre-sal brasilero; Producción de Hidrocarburos; Compañías Internacionales del Petróleo.

\section{INTRODUÇÃO}

As atividades de exploração e produção da Petrobras nas bacias da margem leste brasileira nas décadas de 1960 e 1970 apontaram para o potencial de reservas de petróleo e gás natural na Bacia de Santos (Pereira et al., 1986), sobretudo, depois do início da produção de hidrocarbonetos na Bacia de Campos no final dos anos de 1970 (Pereira e Macedo, 1990).

O tamanho da Bacia de Santos, suas semelhanças geológicas e proximidade com a Bacia de Campos, justificavam a condição de bacia promissora. Entretanto, não representou nenhum sucesso exploratório até o início dos anos 1980 (Pereira e Macedo, 1990).

Essa condição apresentou mudanças significativas com a implementação dos polos de produção de gás natural na década de 1990 e início dos anos 2000, respectivamente, Merluza e Mexilhão (Chang et al., 2008).

A confirmação da viabilidade de explotação dos reservatórios de hidrocarbonetos abaixo da sequência evaporítica no Campo de Parati em 2005, posicionou a Bacia de Santos como a principal bacia receptora dos investimentos em exploração e produção por parte da Petrobras, possibilitando o início de um novo ciclo exploratório e produtivo (Souza e Sgarbi, 2016).

A Bacia de Santos apresenta a maior área a ser explorada no Pré-sal brasileiro (existem outros reservatórios de hidrocarbonetos, no globo terrestre, que estão localizados abaixo de uma seção evaporítica), que a partir das várias descobertas dos reservatórios de petróleo e gás natural sob a sequência dos evaporitos do Aptiano, geraram uma grande expectativa para posicioná-la como a maior bacia produtora de hidrocarbonetos do país (Souza e Sgarbi, 2016).

Outro aspecto importante no tocante a atração dos investimentos para a implantação das unidades de produção na Bacia de Santos deveu-se ao fato dela se posicionar geograficamente adjacente a Bacia de Campos, o que inicialmente possibilitou a diminuição dos custos de implantação da infraestrutura necessária para o desenvolvimento dos trabalhos.

A expansão da produção de petróleo e gás natural na Bacia de Santos desde 2009, ano do início da produção comercial no Campo de Lula, permitiu conter o declínio da produção da Bacia de Campos e ao mesmo tempo aumentar a produção nacional, almejando a autossuficiência energética, que desde o início do século XX se apresentou ao Estado brasileiro como um objetivo quase inalcançável (ANP, 2015c).

Algumas estimativas apontam que o volume das reservas do Pré-sal na Bacia de Santos seja superior a 100 bilhões de barris (Sauer, 2016), posicionando o país entre as cinco maiores reservas mundiais, condição esta que atraiu as atenções da indústria mundial do petróleo (Sauer e Rodrigues, 2016).

O volume potencial das reservas, conjuntamente com as grandes acumulações de óleo leve (Sauer e Rodrigues, 2016), a alta produtividade dos poços produtores, muitos dos quais superando a produção da maior parte das bacias produtoras de hidrocarbonetos no país, permite a progressiva diminuição dos custos de produção do barril de petróleo, estabelecendo uma produção competitiva em relação a outras regiões produtoras no planeta (Nogueira e Gaier, 2017). 
Os principais trabalhos que analisaram especificamente a Bacia de Santos, apresentam foco na geologia de hidrocarbonetos ou geologia e exploração de petróleo e gás natural, do ponto de vista geológico (Pereira et al., 1986; Moreira et al., 2007); geologia e exploração (Pereira e Macedo, 1990; Assine et al., 2008; Chang et al., 2008; Mohriak, 2012).

A ausência de trabalhos científicos que abordem a explotação dos reservatórios de hidrocarbonetos na Bacia de Santos, sobretudo, os localizados abaixo da seção evaporítica do Aptiano, além da geologia e exploração, estabeleceu-se como o fio condutor deste artigo.

O objetivo deste trabalho é analisar as características geológicas da Bacia de Santos e ao mesmo tempo a evolução da exploração e produção de hidrocarbonetos que permitiram a Bacia de Santos tornar-se a maior produtora de petróleo e gás natural do país.

O desenvolvimento do trabalho contou com a análise dos dados secundários disponibilizados pela Agência Nacional do Petróleo, Gás Natural e Biocombustíveis (ANP), Petrobras e British Petroleum, além de uma revisão bibliográfica sobre os seguintes temas:

(i) Evolução tectono-sedimentar da Bacia de Santos.

(ii) Evolução da exploração de hidrocarbonetos nas bacias sedimentares onshore e offshore do Brasil.

(iii) Produção de petróleo e gás natural nas bacias sedimentares onshore e offshore do Brasil.

(iv) Evolução da exploração de hidrocarbonetos na Bacia de Santos.

(v) Produção de hidrocarbonetos na Bacia de Santos.

(vi) Análise do contexto geopolítico do petróleo diretamente impactado tanto pela produção atual quanto futura de petróleo e gás natural da Bacia de Santos.

(vii)Mercado internacional do petróleo diretamente impactado tanto pela produção atual quanto futura de petróleo e gás natural da Bacia de Santos.

O presente artigo contribui para a discussão sobre a importância e relevância da Bacia de Santos tanto para a produção de petróleo e gás natural no Brasil quanto do seu impacto na geopolítica do petróleo e no mercado internacional da commodity.

\section{MATERIAIS E MÉTODOS}

O desenvolvimento do trabalho contou com uma revisão bibliográfica detalhada sobre os assuntos abordados, somado a análise dos dados de produção de petróleo e gás natural das bacias de Campos e Santos e, dos principais fatores que incidem sobre o custo de produção do barril de petróleo no Pré-sal da Bacia de Santos, que são disponibilizados pela ANP, por meio das publicações do Boletim da Produção de Petróleo e Gás Natural e do Anuário Estatístico das diversas edições e, da sua seção de Exploração \& Produção no endereço eletrônico da agência.

Aos dados divulgados pela ANP, somam-se as informações contidas no Plano de Negócios e Gestão da Petrobras para o período 2017-2021 e da publicação British Petroleum Statistical Review of World Energy 2017.

\section{CONTEXTO GEOLÓGICO}

A Bacia de Santos (FIGURA 1) está localizada na margem sudeste do Brasil, entre os Altos de Cabo Frio (ACF) - paralelo 2330'S - e Florianópolis (AF) paralelo $28^{\circ} 00^{\prime} \mathrm{S}$ (Caldas, 2007). Limita-se ao norte com a Bacia de Campos e ao sul com a Bacia de Pelotas, a oeste com a Serra do Mar e a leste com o limite oriental do Platô de São Paulo (Gamboa et al., 2008).

Do ponto de vista geológico a Bacia de Santos apresenta duas características importantes em relação às demais bacias que compartilham o Pré-sal (os reservatórios de hidrocarbonetos abaixo da seção evaporítica estão distribuídos entre as bacias de Santos e SergipeAlagoas): (i) inexistência de porção emersa da bacia (Garcia, 2012), e (ii) ocorrência de magmatismo formador do embasamento na bacia, representado pela Formação Camboriú, do Neocomiano Superior (Moreira et al., 2007) semelhante ao que ocorre também na Bacia de Campos, representado pela Formação Cabiúnas, também do Neocomiano Superior (Filho et al., 2008). 


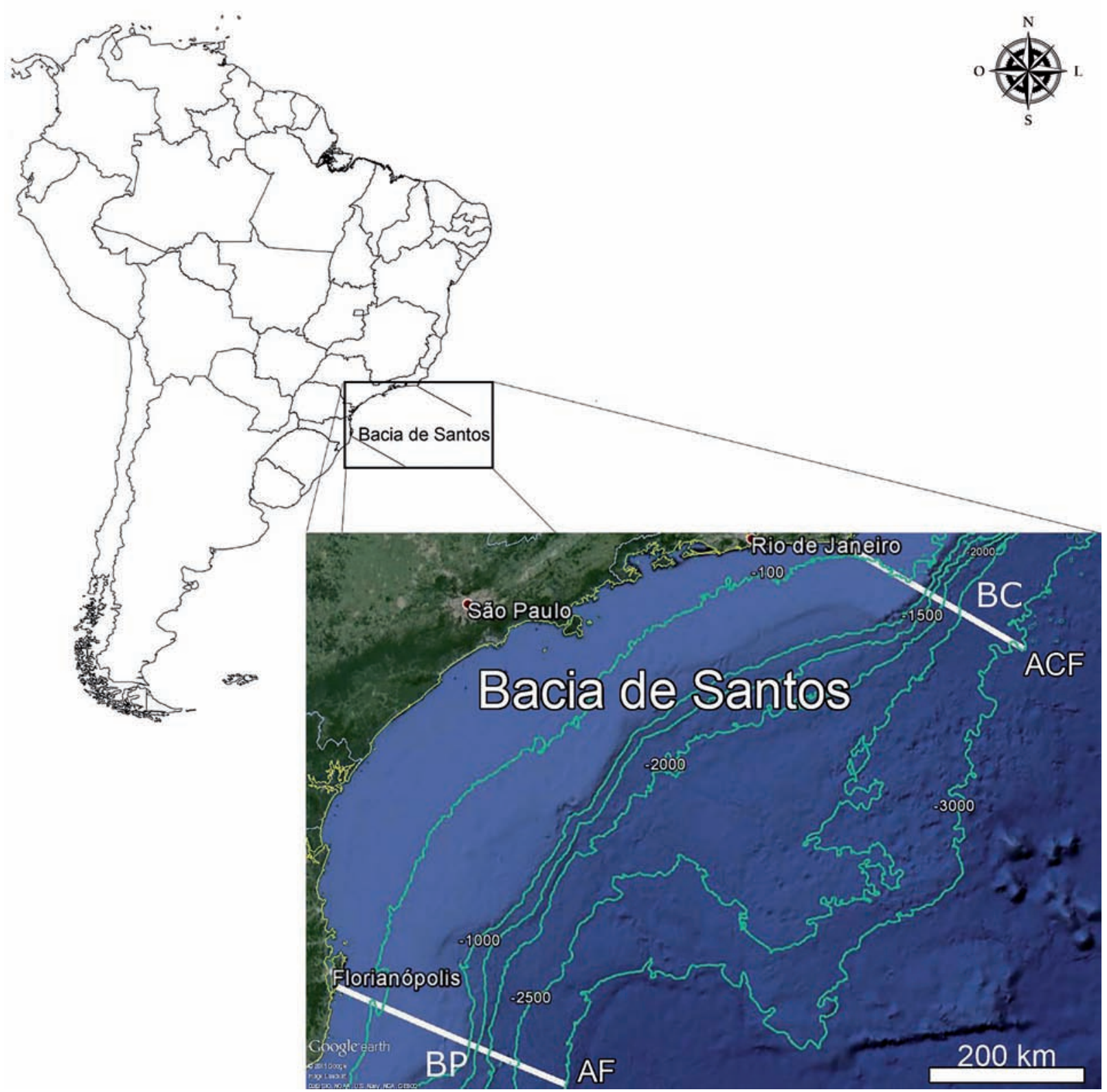

FIGURA 1. Mapa de localização da Bacia de Santos. $\mathrm{BP}=$ Bacia de Pelotas; $\mathrm{AF}=$ Alto de Florianópolis; $\mathrm{ACF}=\mathrm{Alto}$ de Cabo Frio; $\mathrm{BC}=$ Bacia de Campos (modificado de Gamboa et al., 2008; CPRM, 2013).

\section{Evolução tectono-sedimentar}

De acordo com Moreira et al. (2007), a história geológica da Bacia de Santos pode ser dividida em três fases: Rifte, Pós-rifte e Drifte (FIGURA 2).

\section{Fase Rifte}

Os esforços extensionais de separação entre as placas Sulamericana e Africana iniciados a partir do Cretáceo Inferior que culminou com a individualização das placas no Albiano (Mohriak, 2003), atuaram de forma progressiva e diacrônica propagando-se do sul para o norte (Bueno, 2004).

Na Fase Rifte a tectônica extensional atuou como mecanismo formador de espaço para acomodação sedimentar, tendo na subsidência mecânica, o gerador de falhas normais (Milani et al., 2007), além de reativação de falhas no embasamento do Pré-Cambriano (Mohriak, 2003), constituindo blocos falhados e rotacionados com grábens alojando grandes depocentros sedimentares (Milani et al., 2007), representados pela sequência Pré-sal. 
Leonardo Silveira de Souza, Geraldo Norberto Chaves Sgarbi

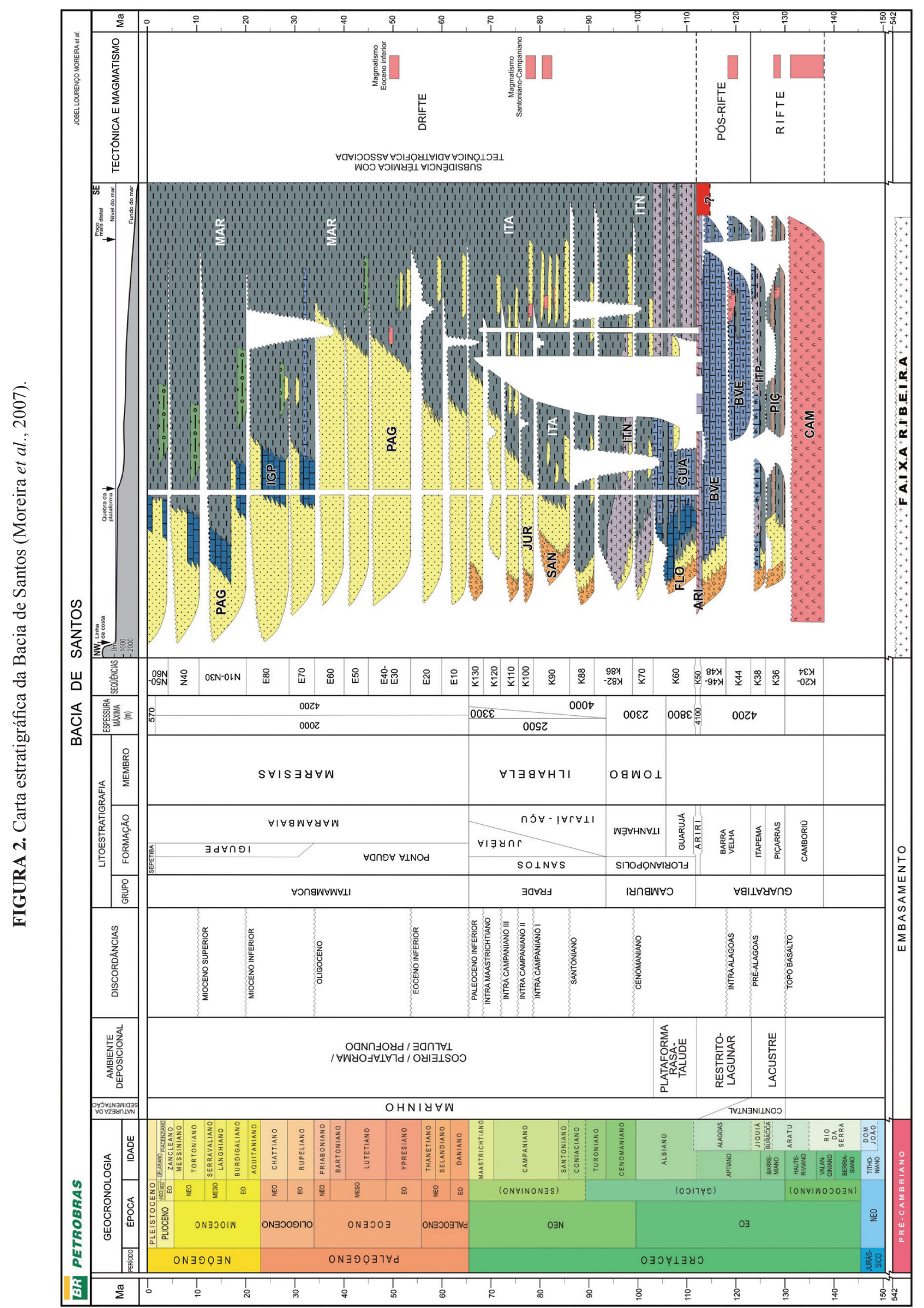


O estiramento da crosta continental foi responsável pela formação do Platô de São Paulo (Moreira et al., 2007), feição fisiográfica de fundamental importância para a sedimentação dos evaporitos na fase Pós-rifte (Mohriak e Szatmari, 2008).

$\mathrm{Na}$ estratigrafia da Fase Rifte, o Grupo Guaratiba engloba as formações Camboriú, Piçarras e Itapema. A primeira formação, engloba os basaltos toleíticos, originados pelos primeiros derrames de lavas que perdurou do Jurássico Superior até o Cretáceo Inferior da Formação Serra Geral, que ocorrem na Bacia do Paraná e estendem-se nas bacias marginais do sudeste do Brasil (Mohriak, 2012).

A Formação Piçarras, diz respeito aos sedimentos de leques aluviais depositados no Andar Barremiano nas porções proximais, representados pelos conglomerados e arenitos polimíticos (fragmentos de basalto, quartzo e feldspato) enquanto os arenitos, siltitos e folhelhos de composição talco estevensítica (silicato hidratado de magnésio/esmectita) englobam as rochas mais distais de ambiente lacustre (Moreira et al., 2007).

Sobrepostos a Formação Piçarras, encontra-se uma discordância na base da Formação Itapema, que por sua vez engloba os sedimentos depositados desde o Neobarremiano ao Eoaptiano. Nas porções proximais ocorrem conglomerados e arenitos com sedimentos de leques aluviais, no restante da sequência ocorrem a intercalação de calcirruditos (constituídos por fragmentos de conchas de pelecípodes que freqüentemente encontram-se dolomitizados e/ou silicificados) e folhelhos escuros (Moreira et al., 2007), ambos depositados nas primeiras incursões marinhas na bacia (Arai, 2014).

\section{Fase Pós-rifte}

O aumento gradual das incursões marinhas que originaram a formação do Oceano Atlântico Sul, foram provenientes do Oceano Atlântico Central, situada na região atual do Caribe (Dias-Brito, 1995; Arai, 2014). Essa bacia, que mostrava uma assembleia de microfósseis do domínio tetiano, foi impedida de alcançar a Bacia de Pelotas ao sul, em virtude da barreira física representada pelo Alto de Florianópolis e a Dorsal de São Paulo (Arai, 2009).
Por sua vez, os trabalhos de Mohriak (2003, 2012) apontam que a sedimentação dos evaporitos no Aptiano decorreu das incursões marinhas provenientes da porção meridional do Oceano Atlântico, que periodicamente transpunham a barreira vulcânica.

Essa barreira vulcânica, ao sul da Bacia de Santos constituía-se em uma estrutura restritiva a circulação da água marinha entre o Atlântico Sul Meridional e o Atlântico Central, situação que só foi superada definitivamente no Neoalbiano (Azevedo, 2004), devido ao aprofundamento da bacia sob o domínio tectônico termal (Mohriak, 2012). Conjuntamente, o clima árido imperante (Arai, 2009) também contribuiu para criar as condições ideais para a acumulação da sequência evaporítica no golfo estreito e alongado que estendia desde a Bacia de Santos até a bacia de Sergipe-Alagoas (Mohriak, 2003, 2012). Sequência esta que se depositou sobre as seções rifte e sag, selando-as.

Durante a deposição dos evaporitos no Aptiano, a subsidência termal dominou sobre os demais processos tectônicos (Gamboa et al., 2008), impactando na grande redução da atividade de falhas normais, permitindo o desenvolvimento de uma segunda bacia com geometria sag (Milani et al., 2007). Todo o pacote evaporítico, com cerca de $2 \mathrm{~km}$ de espessura, localmente formando depósitos estratificados, depositou-se em apenas $600 \mathrm{mil}$ anos (Dias, 2008), evidenciando a anomalamente alta taxa de subsidência ali implantada naquela época.

A movimentação do sal iniciou-se no Aptiano Superior (Mohriak, 2012), gerando uma série de falhas lístricas que se propagam para as camadas do Pós-sal, estabelecendo uma estruturação complexa como os diápiros de sal, almofadas de sal, casco de tartaruga (anticlinal) e muralhas de sal (Mohriak, 2003).

Para Moreira et al. (2007) a estratigrafia da bacia nesta fase apresenta as formações Barra Velha (carbonatos) e Ariri (evaporitos), pertencentes ao Grupo Guaratiba. A primeira formação é subdividida em duas sequências separadas por uma discordância datada em $117 \mathrm{Ma}$, ambas depositadas em ambiente transicional, entre continental e marinho raso desde o Eoaptiano ao Neoaptiano, com a deposição de calcários microbiais, estromatólitos e laminitos nas porções proximais e folhelhos nas porções distais no Eoaptiano além da presença de basaltos datados pelo método Ar/Ar em 117 Ma. 
No Neoaptiano a litologia caracteriza-se por conglomerados e arenitos nas porções proximais enquanto nas distais, ocorrem calcários estromatolíticos e laminitos microbiais, localmente dolomitizados (Moreira et al., 2007).

Sobrepostos a Formação Barra Velha, encontramse os evaporitos da Formação Ariri depositados no Neoaptiano (Moreira et al., 2007) em um ambiente de golfo estreito e alongado (Riccomini et al., 2012), constituídos principalmente por halita e anidrita, além da presença de taquidrita, carnalita e, localmente, silvinita. Seu limite superior é dado pela passagem entre os evaporitos e os sedimentos siliciclásticos/ carbonáticos das formações Florianópolis e Guarujá (Moreira et al., 2007), já no Pós-sal.

\section{Fase Drifte}

Nesta fase a subsidência termal possibilitou o aprofundamento da bacia (Mohriak, 2012) e consequentemente a transposição dos obstáculos vulcânicos no limite sul da depressão (Garcia, 2012), entre o Aptiano e Albiano (Arai, 2014) e a instalação do oceano pleno com a deposição dos sedimentos carbonáticos e posteriomente siliciclástico (Gamboa et al., 2008).

Esta etapa evolutiva também pode ser caracterizada pela transição de crosta continental para crosta oceânica (Mohriak, 2003), com a individualização das placas sulamericana e africana (Riccomini et al., 2012), determinando o término da bacia evaporítica (Mohriak, 2003).

Inicialmente o ambiente marinho na bacia érepresentado pelos sedimentos de águas rasas seguido de expansão do fundo oceânico, aumento da batimetria seguido da deposição sedimentar de águas profundas (Souza, 2008), que encontra na sedimentação turbidítica a gênese de vários reservatórios de hidrocarbonetos do Pós-sal da Bacia de Santos (Mohriak, 2012).

No Cretáceo Superior houve uma reativação de antigas falhas do embasamento, causando o soerguimento das Serra do Mar e da Mantiqueira, o que ocasionou notável erosão e progradação siliciclástica de cunhas detríticas para dentro da bacia (Macedo, 1987, 1989; Almeida e Carneiro, 1998 apud Souza, 2008).

Do ponto de vista estratigráfico, a bacia nesta fase constitui-se dos Grupos: Camburi, Frade e Itamambuca (Moreira et al., 2007), que por sua vez representam três etapas do desenvolvimento tectonosedimentar da Fase
Drifte, impactada pela variação eustática, pelo aporte sedimentar e pela tectônica do sal (Garcia, 2012).

Para Moreira et al. (2007), o Grupo Camburi representa todos os sedimentos depositados desde os leques aluviais até os pelitos e arenitos batiais que foram depositados após a Formação Ariri até o topo do Cenomaniano. Esta unidade engloba as formações Florianópolis, Guarujá, Itanhaém e o Membro Tombo, incluso na Formação Itanhaém. Este grupo representa uma fase transgressiva que culmina com a deposição dos folhelhos anóxicos da transgressão Turoniana.

O Grupo Frade é formado pelas formações Santos, Juréia, Itajaí-Açu e o Membro Ilha Bela que foi definido por Pereira et al. (1986). A unidade representa todos os sedimentos depositados desde os leques aluviais até os pelitos e arenitos batiais que foram depositados do topo do Cenomaniano até o limite Cretáceo/ Paleógeno (Moreira et al., 2007).

As sequências deposicionais desse grupo engloba uma fase de regressão marinha onde o limite da plataforma avançou até $200 \mathrm{~km}$ costa adentro (Moreira et al., 2007), gerada pelo soerguimento da Serra do Mar que aportou um grande volume de sedimentos siliciclásticos em direção a bacia, provocando o deslocamento do sal aptiano para as porções mais distais (Assine et al., 2008).

O Grupo Itamambuca, definido por Moreira et al. (2007), representa todos os sedimentos depositados após o limite Cretáceo/Paleógeno até os dias atuais. Esta unidade abarca os depósitos de leques aluviais proximais até pelitos e arenitos batiais, com ocorrências de sedimentação mista carbonática próximo à quebra da plataforma (Garcia, 2012).

A unidade estratigráfica Itamambuca compreende as formações Ponta Aguda, Iguape, Marambaia com a definição dada por Moreira et al. (2007) do Membro Maresias e no topo das sequências, a Formação Sepetiba.

\section{EXPLORAÇÃO E PRODUÇÃO DE PETRÓlEO E GÁS NATURAL NO BRASIL}

A necessidade de encontrar reservatórios de hidrocarbonetos que pudessem levar o país a autossuficiência energética norteou os esforços do Estado brasileiro por quase todo o século 20, por meio dos investimentos nas atividades de exploração e produção realizados pela Petrobras e no treinamento do corpo técnico da companhia (Mendonça et al., 2004). 
As atividades de exploração e produção que antecederam a viabilidade da explotação dos reservatórios de petróleo e gás natural do Pré-sal brasileiro no bloco BM-S-10 (Campo de Parati) na Bacia de Santos em 2005 (ANP, 2015a), podem ser resumidos em 2 fases principais, assim descritas:

\section{$1^{\circ}$ Fase: exploração e produção terrestre}

$\mathrm{O}$ embrião da indústria nacional de hidrocarbonetos remonta a segunda metade do século XIX com as duas concessões outorgadas em 1858 pelo Imperador Dom Pedro II a particulares, para a pesquisa e mineração de carvão, turfa e betume (Milani et al., 2000).

Com a importância da fonte fóssil para o desenvolvimento da indústria após a $1^{\circ}$ Guerra Mundial, foi estabelecido no Brasil, a institucionalização da indústria do petróleo em 1938, com a criação do Conselho Nacional do Petróleo (CNP), que lançou as primeiras diretrizes para a implementação das atividades de exploração e produção no país (Mendonça et al., 2004).

Com a criação da Petrobras em 1953, exercendo o monopólio das atividades de exploração e produção de hidrocarbonetos, a estatal administrou o acervo das descobertas na Bacia do Recôncavo Baiano (Mendonça et al., 2004), bacia pioneira em termos de confirmação do potencial exploratório e da viabilidade comercial da explotação (Milani et al., 2000), além da Bacia de Sergipe-Alagoas (Aquino e Lana, 1990) e recebeu a base conceitual de gestão para a implantação de uma estrutura de exploração que permitiu, de forma organizada, avaliar o potencial petrolífero das bacias sedimentares brasileiras (Mendonça et al., 2004).

As atividades exploratórias iniciais da Petrobras centraram, sem sucesso, nas bacias paleozoicas brasileiras (Mendonça et al., 2004), além das bacias marginais terrestres representadas pelas bacias do Recôncavo e Sergipe-Alagoas (Zalán, 2012), obtendo sucesso apenas relativo (Aquino e Lana, 1990), semelhantes as ocorridas no período do CNP, fase esta coordenada pelo geólogo norte-americano Walter Link, com uma estrutura exploratória baseada na presença de técnicos norte-americanos (Mendonça et al., 2004).

Apesar da expectativa governamental, o "Relatório Link" em 1960 apresentou poucos resultados positivos. A partir de então, coube ao geólogo brasileiro Pedro de Moura, conjuntamente com técnicos brasileiros em 1961, a tarefa de definir os novos caminhos da exploração de petróleo no Brasil (Mendonça et al., 2004).
Nesta nova fase, o direcionamento das atividades de exploração da Petrobras nas bacias do Recôncavo e Sergipe-Alagoas sob a coordenação de técnicos brasileiros, permitiu o sucesso exploratório na porção emersa da Bacia de Sergipe - Alagoas que culminou com a descoberta do Campo de Carmópolis em 1963 (Aquino e Lana, 1990), fator que impulsionou a Petrobras a ampliar as atividades de exploração em direção a plataforma continental brasileira.

\section{$2^{\circ}$ Fase: exploração e produção marítima}

Para Zalán (2012), ao final da década de 1960 não havia outro caminho para a Petrobras a não ser a exploração das bacias marinhas porque a exploração das bacias intracratônicas brasileiras de idade paleozoica (Bacias do Paraná, Parnaíba e o conjunto de bacias que compõem a Bacia Amazônica) não haviam correspondido aos grandes esforços do Estado brasileiro, na busca pela expansão da produção nacional de petróleo, despendidos nas décadas de 1950 e 1960.

A aquisição, entre 1957 e 1966, de dados de refração e reflexão sísmica, além da perfuração de uma série de poços estratigráficos ao longo de toda a costa, entre as bacias de Barreirinhas e Pelotas (Mendonça et al., 2004) gerou conhecimento para a perfuração do primeiro poço (1-ESS-1) na Bacia do Espírito Santo em 1968 (Mohriak, 2012).

O ano de 1968 também marcou a descoberta do Campo de Guaricema (FIGURA 3), em reservatórios em arenitos turbidíticos, na Bacia de Sergipe-Alagoas, o primeiro offshore do país (Zalán, 2012).

O sucesso exploratório inicial da Bacia de SergipeAlagoas determinou o direcionamento para as descobertas de reservatórios turbidíticos (Aquino e Lana, 1990). Entretanto, no início dos anos 1970, o foco da exploração foi desviado momentaneamente para as rochas carbonáticas, em decorrência da descoberta, em 1974 do primeiro campo de petróleo na Bacia de Campos, o Campo de Garoupa (FIGURA 3) em carbonatos albianos, que precedeu a várias descobertas nesta bacia em reservatórios carbonáticos (Zalán, 2012).

Embora os reservatórios presentes nessas rochas carbonáticas tenham atraído às atenções dos exploracionistas a partir da descoberta do Campo de Garoupa (Mendonça et al., 2004), na medida em que se perfurava nos carbonatos albianos, eram descobertos reservatórios em turbiditos mais jovens com 
profundidades menores, apresentando bons resultados exploratórios como o Campo de Namorado em 1975, nos turbiditos de idade albiana (Zalán, 2012).

O sucesso exploratório inicial com turbiditos nas bacias de Sergipe e Campos espalhou-se pelas bacias marginais da margem leste, transformando-se no principal alvo exploratório da Petrobras. Produções de óleo e gás nestes tipos de reservatórios foram estabelecidas nas águas rasas (lâminas d'água inferiores a $300 \mathrm{~m}$ ) nas bacias do Ceará, Potiguar, Sergipe, Espírito Santo, Campos e Santos (Zalán, 2012).

Para Zalán (2012) a partir dos resultados positivos em águas rasas, os exploracionistas, sob a coordenação de Carlos Walter Marinho Campos, previram que os turbiditos que estavam sendo encontrados com petróleo nas águas rasas das plataformas continentais das bacias marginais se estenderiam em direção as águas profundas (entre 700 e 1.500 metros) e, se espessariam de maneira significativa, propiciando então condições para a descoberta de campos gigantes.

A Petrobras, ao se lançar na exploração em lâminas de água superior a $300 \mathrm{~m}$, proporcionou a aquisição do primeiro levantamento sísmico tridimensional para a Bacia de Campos em 1978 (Mendonça et al., 2004), logrando resultados positivos nos anos 1980 e 1990 (FIGURA 3), com a descoberta de campos gigantes nos reservatórios turbidíticos em águas profundas e ultraprofundas (FIGURA 3), culminando com a maior descoberta petrolífera no país, o Campo de Roncador, nessa bacia (Zalán, 2012).

As atividades de exploração e produção na margem continental leste brasileira executadas pela Petrobras até a viabilidade da explotação de hidrocarbonetos nos reservatórios do Pré-sal brasileiro, permitiram a geologia nacional a quebra de dois paradigmas: a importância dos turbiditos como reservatórios de petróleo, e a capacidade de folhelhos lacustres (depositados na Fase Rifte) gerarem quantidades gigantescas deste insumo, que foram responsáveis por todo o óleo descoberto nas bacias de Campos, Recôncavo, Sergipe-Alagoas e Potiguar (Zalán, 2012).

Para Zalán (2012) no início dos anos 2000 havia um novo dogma que estava em processo de formação, que era a ocorrência de apenas óleo pesado nas bacias marginais do sudeste brasileiro, quando foram encontradas varias jazidas de óleo leve nas bacias do Espírito Santo e Campos, tanto em turbiditos (Campo de Golfinho) como em carbonatos (descobertas dos campos de Jabuti, Jurará, Suruaña e Aruaña).

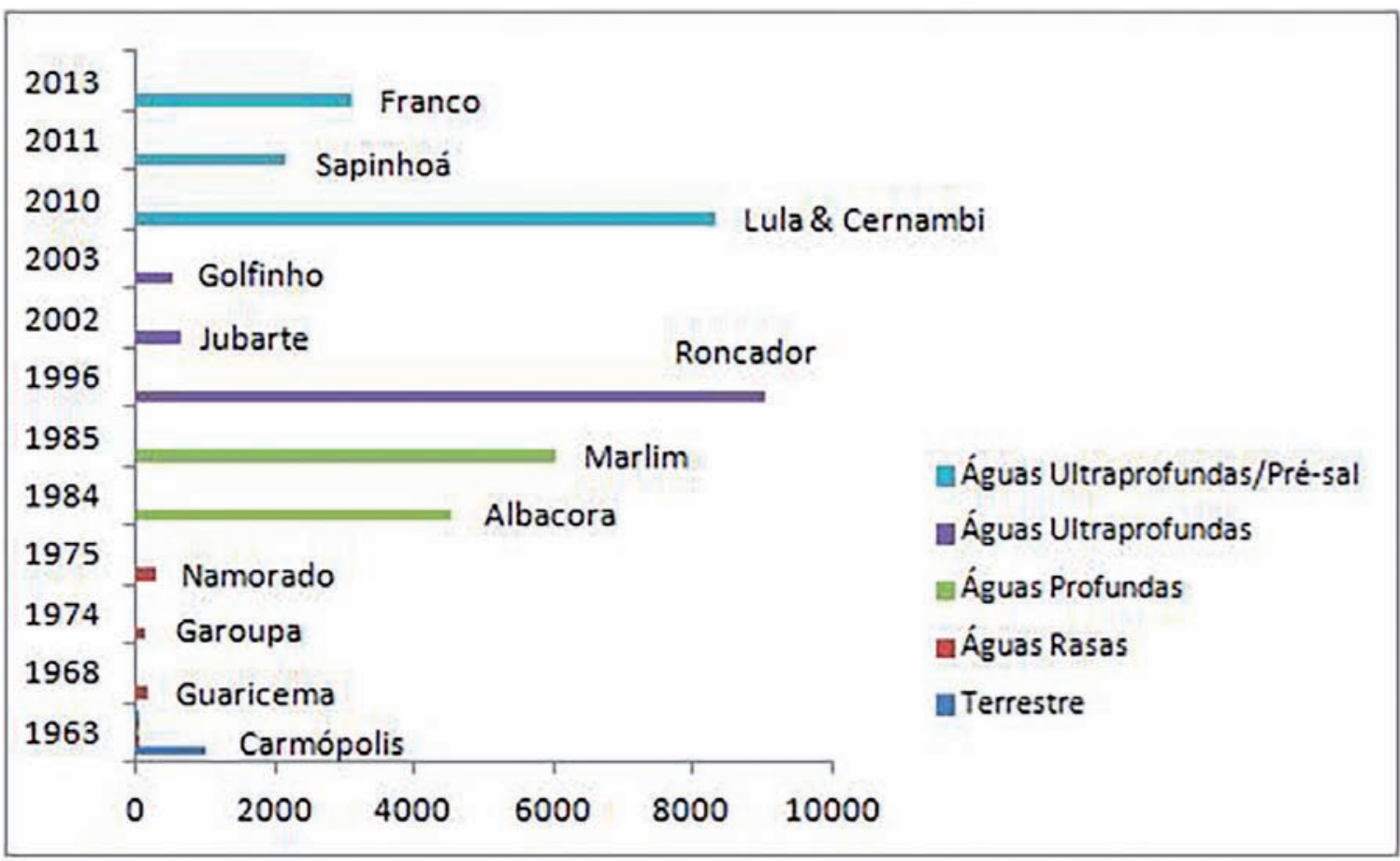

FIGURA 3. Evolução do volume das reservas dos principais campos de petróleo descobertos no país. Em milhões de barris de óleo equivalente (boe). Modificado de Aquino e Lana (1990), Mendonça et al. (2004) y ANP (2015a). 


\section{Exploração e produção no Pré-sal}

O modelo de exploração e produção de hidrocarbonetos na margem continental leste a partir de 2005 apresenta mudança em termos da idade dos reservatórios de hidrocarbonetos explotados, que pode ser assim descrito:

(i) Nas primeiras quatro décadas de produção offshore, são acumulações de hidrocarbonetos com idades variando do final do Cretáceo Inferior ao Terciário (Mohriak, 2012), denominados de Pós-sal.

(ii) $\mathrm{Na}$ segunda metade da década passada, iniciou a produção dos reservatórios do Pré-sal, ou seja, os sedimentos lacustres posicionados abaixo da seção evaporítica de idade aptiana, cuja idade das rochas geradoras remonta a Fase Rifte (Biassusi et al.,1990) e estão localizadas desde as bacias da margem sudeste (FIGURA 4) até a Bacia de Sergipe-Alagoas (Mohriak e Szatmari, 2008).

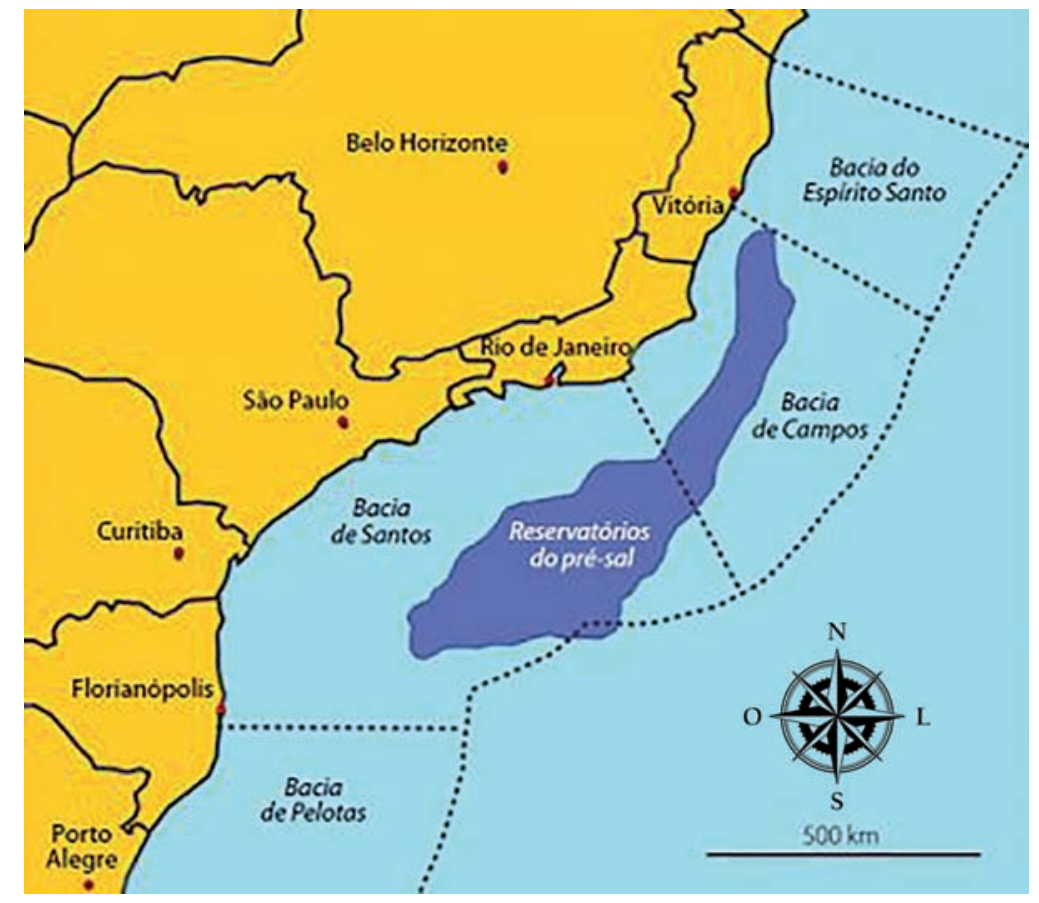

FIGURA 4. Distribuição das rochas reservatórios do Pré-sal (em azul escuro) em relação às bacias sedimentares da margem continental sudeste brasileira. Tomado de Riccomini et al. (2012).

O modelo de exploração e produção de petróleo e gás natural no Pré-sal brasileiro também apresenta condições singulares tanto em relação às espessuras das lâminas de água oceânica quanto de profundidades das perfurações, situação não inédita na Petrobras (em várias oportunidades ao longo de sua história estabeleceu recordes internacionais na produção offshore).

As atividades de upstream no offshore brasileiro iniciaram-se com um poço em lâmina de água de 28 metros ao final da década de 1960 , perfurado no Campo de Guaricema na Bacia de Sergipe-Alagoas (Morais, 2013) e evoluíram até atingir lâmina de água acima de 2.000 metros na década passada, no Campo de Lula na Bacia de Santos (FIGURA 5). Em termos de profundidade de perfuração, saltou de 3.500 metros em meados da década de 1970 (Morais, 2013) para ultrapassar a barreira dos 6.000 metros em 2008 (FIGURA 5).

Os reservatórios do Pré-sal brasileiro são rochas carbonáticas, com os sedimentos depositados há cerca de 120 milhões de anos atrás, nos quais apresentam altos valores de porosidade e permeabilidade para aquelas elevadas profundidades (Zalán, 2012).

A vanguarda do modelo de reservatórios de hidrocarbonetos do Pré-sal, decorre do acúmulo de conhecimentos geológico e geofísico do corpo técnico da Petrobras sobre a margem leste brasileira ao longo dos últimos 60 anos, desde a perfuração do primeiro poço offshore, ESS-1, localizado na Bacia do Espírito Santo (Mendonça et al., 2004). 


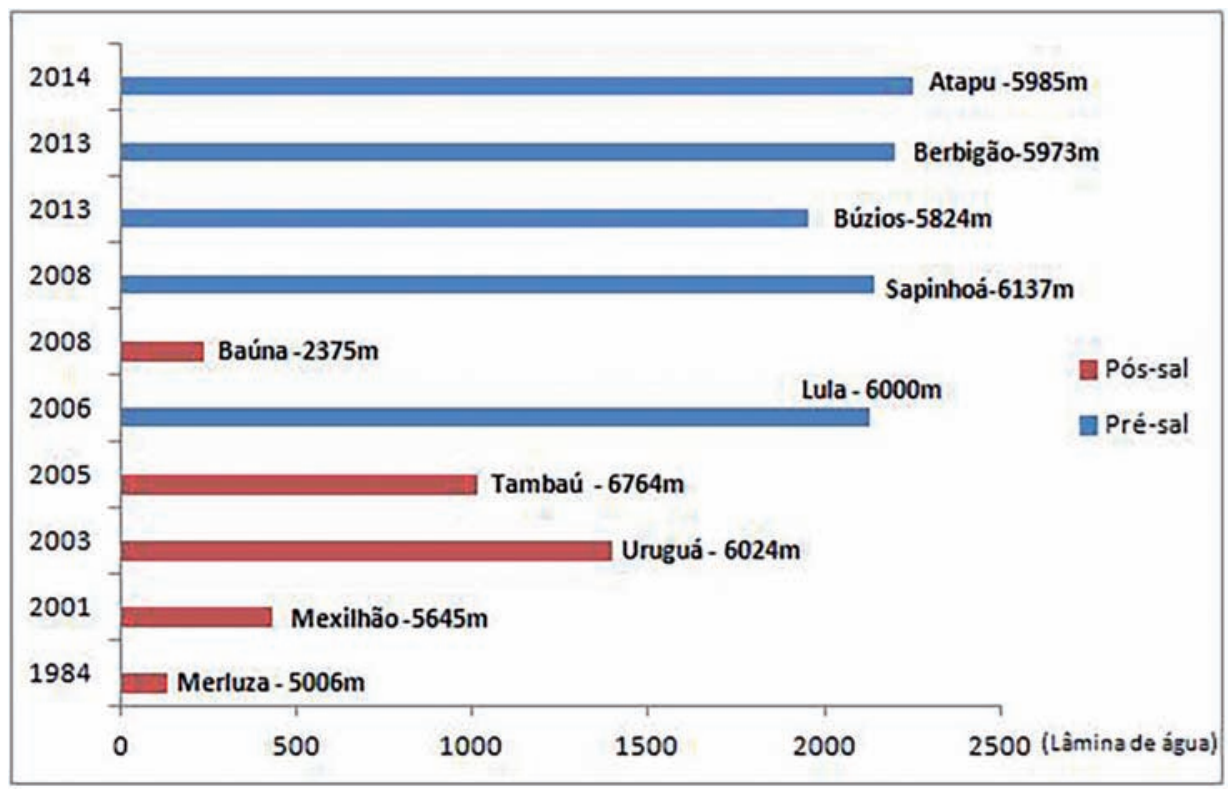

FIGURA 5. Evolução temporal das espessuras da lâmina de água com as respectivas profundidades de perfuração em metros das operações nos campos produtores da Bacia de Santos. Modificado de ANP (2015a).

O modelo geológico de exploração dos reservatórios do Pré-sal brasileiro foi desenvolvido sob a coordenação de Guilherme Estrella (Estrella, 2014), que possibilitou a descoberta de vários campos desde 2005, identificados na FIGURA 6, os quais receberam a denominação de Cluster da Bacia de Santos.

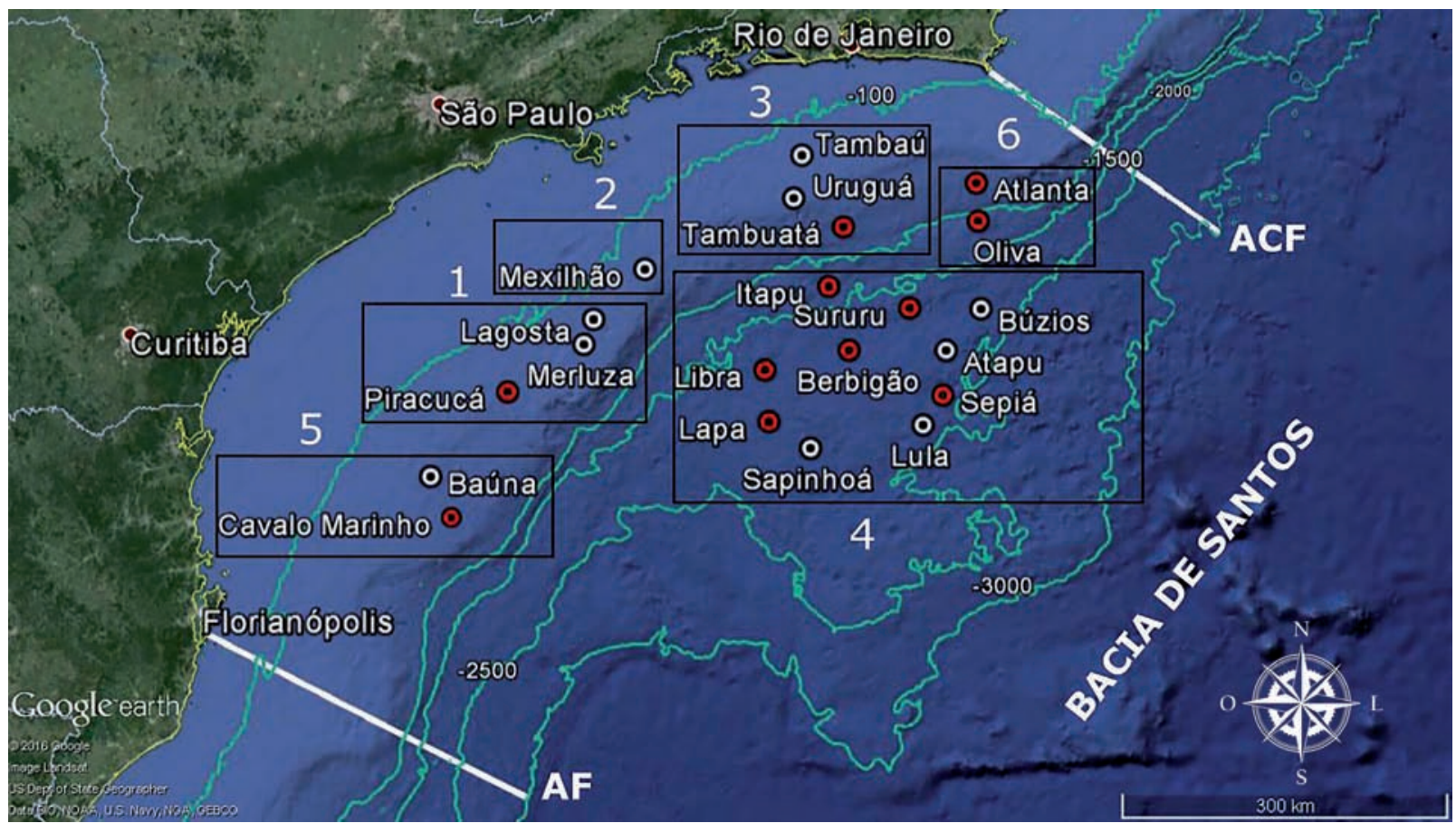

FIGURA 6. Os Polos produtores de petróleo e gás natural da Bacia de Santos. Campos produtores identificados com a cor branca, e, em desenvolvimentos identificados com a cor vermelha. Os números 1,2,3,4,5 e 6= polos de produção. Elaboração dos autores a partir dos dados da ANP (2015a). 


\section{Exploração e produção na Bacia de Santos}

A exploração da Bacia de Santos, iniciada no final da década de 60 , e com ampla contribuição dos contratos de risco celebrados entre a Petrobras e companhias petroleiras internacionais entre 1976 a 1988, encontrava-se em uma fase de relativo pessimismo até 1984, quando a Pecten descobriu o campo de gás de Merluza (Pereira e Macedo, 1990), sendo os reservatórios formados em arenitos turbidíticos pertencentes ao Membro Ilha Bela da Formação ItajaíAçu de idade neo-turoniana a eo-santoniana (Chang et al., 2008).

No início dos anos 2000, a bacia apresentou novas acumulações de gás em sua porção oeste com o Campo de Mexilhão em 2001 (ANP, 2010), tornando-a exclusivamente um polo de produção de gás natural (FIGURA 6), condição esta que perdurou até a segunda metade da década passada, quando iniciou a produção de petróleo nos campos do Póssal de Tambaú e Uruguá em 2009.

O Campo de Mexilhão apresenta reservatórios em arenitos do Membro Ilha Bela da Formação ItajaíAçu de idade do Turoniano ao Maastrichtiano e com reservas de 600 bilhões de barris de óleo equivalente (boe) de gás natural (Vieira, 2009).

Em 2004 com a declaração de comercialidade do Campo de Lagosta, reservatórios em arenitos do Membro Ilha Bela da Formação Itajaí-Açu de idade do Santoniano (ANP, 2015e), que apresentaram volume de 30,8 bilhões de boe (Vieira, 2009), permitiram a constituição do segundo polo de gás natural da bacia (FIGURA 6).

Em 2005 a Petrobras declarou a comercialidade dos campos de Tambaú e Uruguá (Petrobras, 2005) no norte da bacia. Apresentaram no primeiro, reservatórios em arenitos do Membro Tombo da Formação Itanhaém, com idade do Neoalbiano e reservas de 283 bilhões de boe. No segundo, apresentou arenitos do Membro Ilha Bela da Formação Itajaí-Açu, de idade do Turoniano ao Maastrichtiano e com volume de reservatórios de 178 bilhões de boe (Vieira, 2009), estabelecendo o primeiro polo de produção concomitante de petróleo e gás natural e o terceiro da bacia (FIGURA 6).

O ano de 2005 também estabelece um novo modelo exploratório e produtivo de hidrocarbonetos na margem continental leste do Brasil por parte da Petrobras, com a produção em reservatórios do Pré-sal brasileiro no bloco BM-S-10 (Campo de Parati) da Formação Barra Velha do Aptiano da Bacia de Santos (GCA, 2010).

Após as sucessivas descobertas na porção centronorte da Bacia de Santos estabeleceu-se o quarto polo de produção de hidrocarbonetos, denominado Cluster do Pré-sal da Bacia de Santos (FIGURA 7), onde os reservatórios carbonáticos são encontrados em profundidade superior a 5.000 metros, abaixo da camada de sal da ordem média de 2.000 metros (Zalán, 2012).

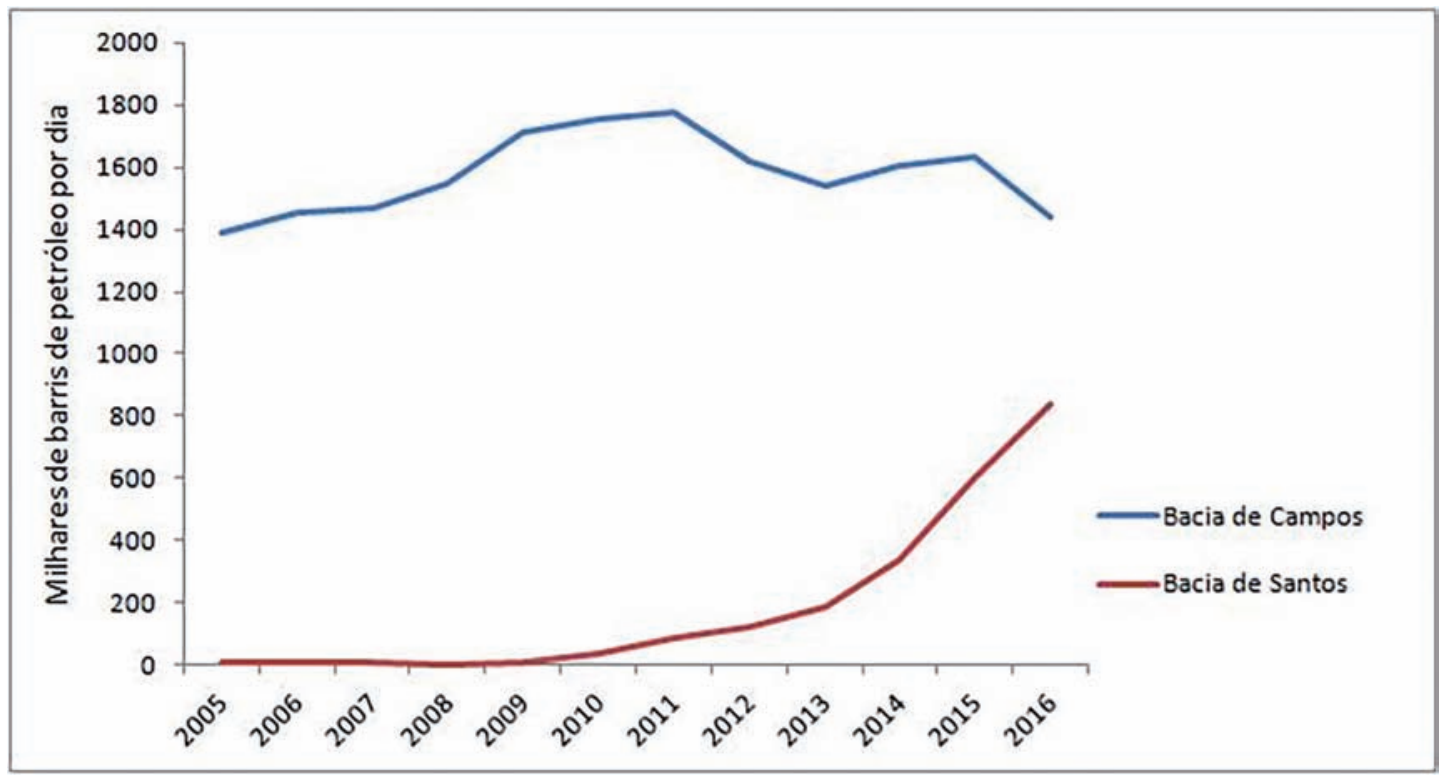

FIGURA 7. Produção de petróleo em milhão de barris/dia nas bacias de Campos e Santos entre 2005 e 2016 . Elaboração dos autores a partir dos dados da ANP (2017a). 
Após o anúncio oficial pela Petrobras da viabilidade da explotação dos reservatórios de petróleo e gás natural no Pré-sal brasileiro em 2005, várias descobertas ocorreram no Cluster de Santos, permitindo a produção em alguns campos: Lula, Sapinhoá, Búzios, Berbigão e Atapu, formando, desta maneira, o quarto polo produtor (FIGURA 6). Por sua vez, os campos de Itapu, Sururu, Lapa, Sepiá e Libra que deverão entrar na fase de produção até o final da atual década (ANP, 2015a), destes, os campos de Sururu e Lapa já estão em operação.

O quinto polo de produção de hidrocarbonetos da bacia, estabeleceu-se a partir da declaração de comercialidade do Campo de Baúna em 2008, apresentando reservatórios em arenitos oligocênicos do Membro Maresias da Formação Marambaia, com volume de reservas de 113 milhões de boe (Petrobras, 2012), predominantemente de óleo (ANP, 2015d) e localizados na porção sul da bacia (FIGURA 6).

O sexto polo de produção de hidrocarbonetos foi implantado com a entrada em produção no mês de maio de 2018 do Campo de Atlanta (QGEP, 2018b), operado pela Queiroz Galvão Exploração e Produção (QGEP), onde os reservatórios de petróleo e gás natural são arenitos turbidíticos da Formação Marambaia com idade eocênica (ANP, 2012).

A produção de hidrocarbonetos nos reservatórios do Pós-sal no Campo de Atlanta, operado pela Queiroz Galvão Óleo e Gás, representa o início de suas operações na Bacia de Santos, além de ser um marco na produção de petróleo e gás natural nesta bacia, que até então, contava somente com a presença da Petrobras (Ramalho, 2018).

O Campo de Oliva, também localizado no sexto polo, encontram-se reservatórios de hidrocarbonetos em arenitos turbidíticos da Formação Marambaia com idade do Paleoceno Superior/Eoceno Inferior (ANP, 2013). O início da produção de petróleo e gás natural do Campo de Oliva está previsto para 2021, a operação do campo será da QGEP (QGEP, 2018a).

Os campos de Atlanta e Oliva estão localizados próximo ao limite com a Bacia de Campos (FIGURA 6).

\section{RESULTADOS}

O início da produção do Campo de Lula em reservatórios do Pré-sal, e dos subsequentes campos produtores de Sapinhoá, Búzios, e Atapu, além das futuras áreas do Cluster do Pré-sal da Bacia de Santos, transformarão a bacia que era promissora até o início dos anos 2000, na maior produtora de petróleo e gás natural do Brasil.

A Bacia de Campos, a maior produtora de petróleo do país desde o final dos anos setenta, apresenta uma produção a partir de 2007 , superior a 1,5 milhão de barris de petróleo/dia, superando a marca de 1,75 milhão de barris de petróleo/dia no primeiro semestre de 2011, quando iniciou uma trajetória de queda até meados de 2013, motivado pela baixa produtividade dos campos do Pós-sal. Neste ano, mesmo com o crescimento da produção, em virtude do início da produção dos reservatórios do Pré-sal na bacia, não conseguiu conter a retração da produção nos anos seguintes (FIGURA 7).

Por sua vez a Bacia de Santos, ao analisarmos a FIGURA 7, apresentou uma produção praticamente nula entre 2005 e 2009, quando inicia um aumento quase que constante a partir de 2009, motivado pela entrada em operação dos polos de produção do Pós-sal, Uruguá, e o do Cluster do Pré-sal da Bacia de Santos a partir do início da produção do Campo de Lula.

A alta produtividade dos poços produtores no Présal brasileiro, sobretudo os da Bacia de Santos tem possibilitado a redução progressiva dos custos de produção do barril de petróleo, a ponto de ser inferior a sete dólares o custo médio da unidade (Nogueira e Gaier, 2017), incentivando a perfuração de novos poços nos campos já em operação com o intuito de reduzir ainda mais o custo de produção.

Dos 10 maiores poços produtores no Pré-sal brasileiro, todos estão localizados na Bacia de Santos (TABELA 1), os seus volumes de petróleo e gás natural produzidos superam algumas das tradicionais bacias produtoras de hidrocarbonetos do Brasil, exemplos das bacias de Sergipe, Camamu e Alagoas (FIGURA 8). 
TABELA 1. Os 10 maiores poços produtores no Pré-sal brasileiro. Modificado de: ANP (2017b).

\begin{tabular}{cccccc}
\hline Nome ANP do poço & Campo & Bacia & Petróleo $(\mathbf{b b l} / \mathbf{d})$ & Gás natural $\left(\mathbf{M m}^{\mathbf{3}} / \mathbf{d}\right)$ & Produção total $(\mathbf{b o e} / \mathbf{d})$ \\
\hline 7LL84DRJS & Lula & Santos & 31.297 & 1.048 & 37.887 \\
7LL83DRJS & Lula & Santos & 28.649 & 1.339 & 37.071 \\
7LL80DBRJS & Lula & Santos & 30.696 & 1.002 & 36.998 \\
7SPH7DSPS & Sapinhoá & Santos & 30.507 & 1.013 & 36.878 \\
9LL20DRJS & Lula & Santos & 28.065 & 1.363 & 36.637 \\
7LL36ARJS & Lula & Santos & 27.814 & 1.324 & 36.145 \\
8LL81DRJS & Lula & Santos & 29.287 & 1.025 & 35.734 \\
7LL15DRJS & Lula & Santos & 29.281 & 1.010 & 35.636 \\
8LL37DRJS & Lula & Santos & 27.240 & 1.323 & 35.559 \\
7SPH1SPS & Sapinhoá & Santos & 29.077 & 966 & 35.154 \\
\hline
\end{tabular}

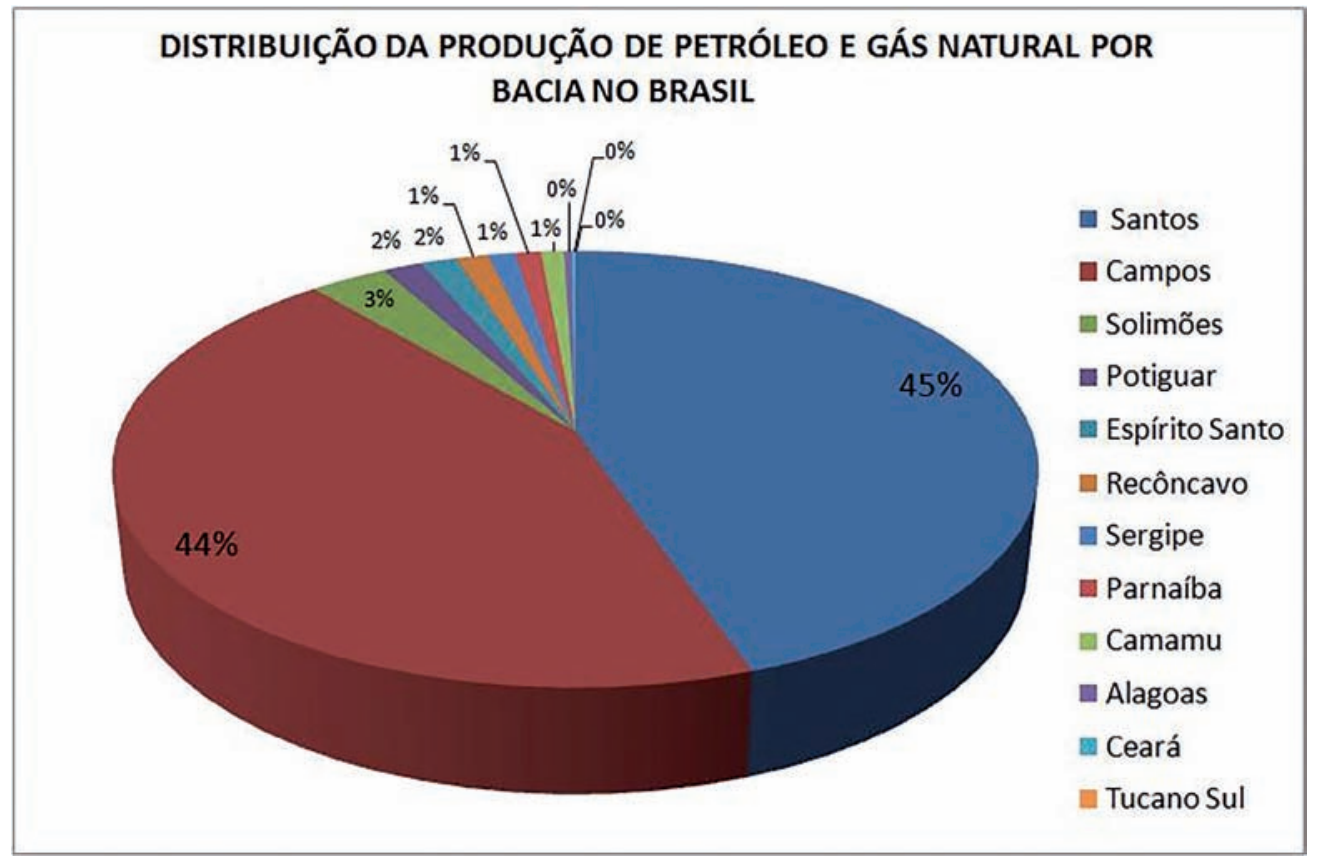

FIGURA 8. Distribuição da produção de petróleo e gás natural por bacia no Brasil em setembro de 2017. Modificado de: ANP (2017b).

As condições geológicas singulares e a extensão da área do Pré-sal na Bacia de Santos, a posicionou como prioridade dos investimentos por parte da Petrobras nas atividades de exploração e produção, que possibilitou a Bacia de Santos suplantar a Bacia de Campos em março de 2015 (ANP, 2015b), a produção de gás natural e, em setembro de 2017 a produção somada de petróleo e gás natural da Bacia de Campos (FIGURA 8), que desde o final dos anos setenta era a maior produtora de hidrocarbonetos do país.

A Bacia de Santos continuará a ser a principal destinatária dos investimentos da Petrobras em exploração e produção no Pré-sal brasileiro, cujo montante será de 40 bilhões de dólares para o período 2017-2021 (Petrobras, 2016b).

Atualmente a Petrobras explota os reservatórios das sequências Pós-sal e Pré-sal da Bacia de Santos por meio de 11 plataformas, este número será ampliado com a entrada em operação de 15 plataformas até 2021 (FIGURA 9) de um total de 21 unidades de produção, de acordo com o Plano de Negócios e Gestão da empresa para o período (Petrobras, 2016b), permitindo assim a consolidação da Bacia de Santos como a maior produtora nacional de hidrocarbonetos. 


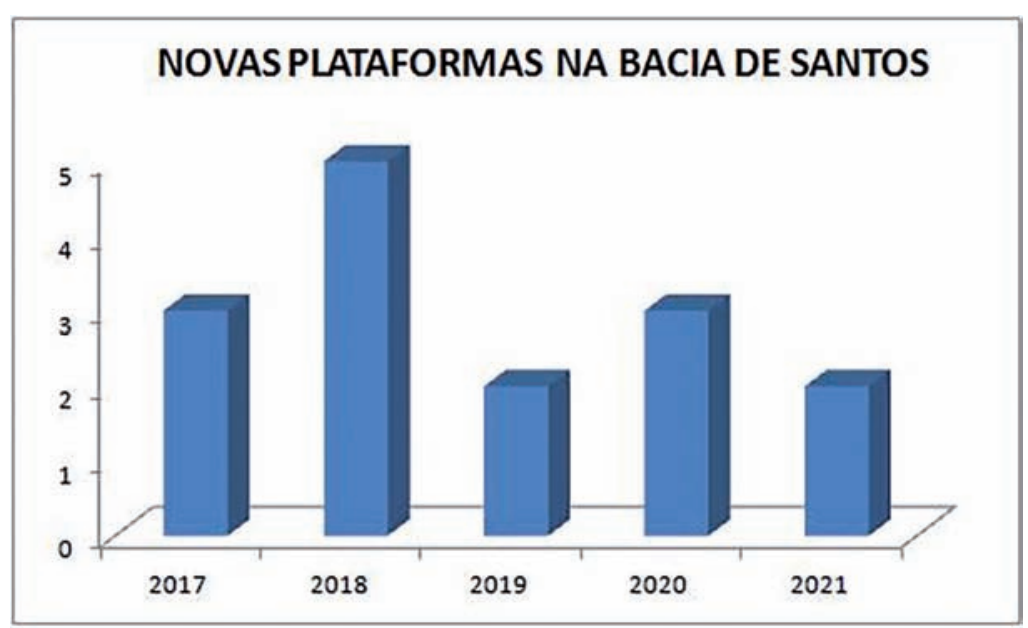

FIGURA 9. As novas plataformas da Petrobras que entrarão em operação na Bacia de Santos entre 2017 e 2021. Modificado de: Petrobras (2016b).

\section{DISCUSSÃO}

Ao apresentar a maior área do Pré-sal brasileiro, a Bacia de Santos mostra o maior potencial de exploração e produção de petróleo e gás natural das bacias na margem leste brasileira.
A viabilidade da explotação dos reservatórios de hidrocarbonetos abaixo da sequência evaporítica, em especial da Bacia de Santos (FIGURA 10), representa para a Petrobras e o país a possibilidade de concretização da tão almejada autossuficiência energética que o Brasil persegue desde o início do século XX.

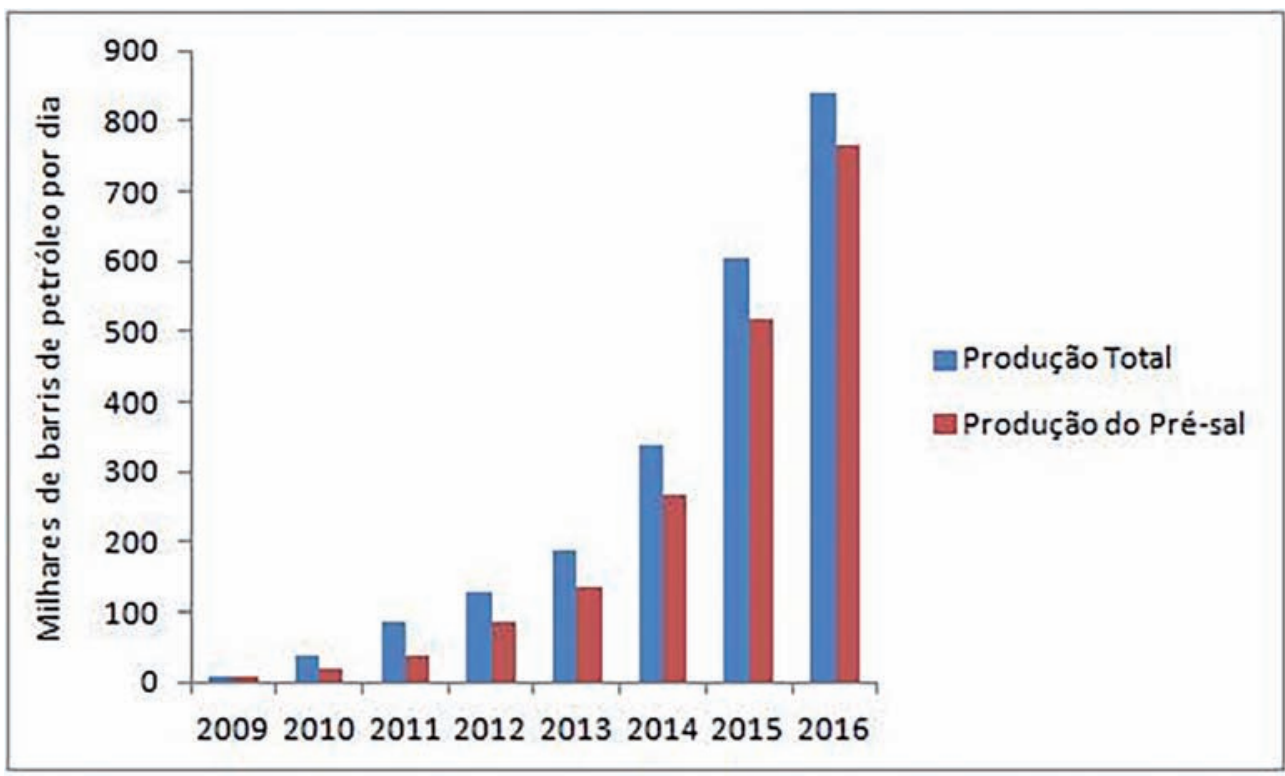

FIGURA 10. Produção de petróleo total e do Pré-sal da Bacia de Santos. Modificado de: ANP (2017c). 
Diferentemente de outros dois momentos importantes na história da indústria nacional do petróleo, o monopólio e a abertura do mercado, o volume das reservas, produção, vazão, qualidade do óleo e a alta taxa de sucesso nas perfurações, principalmente na Bacia de Santos, impôs a necessidade de estabelecer um novo marco regulatório (partilha da produção) para a exploração e produção na área do Pré-sal brasileiro que visasse o aumento da arrecadação pelo Estado brasileiro, além de fortalecer a Petrobras como o único operador dos campos produtores.

Ao estabelecer um novo modelo de exploração e produção de hidrocarbonetos na margem leste brasileira, o Pré-sal brasileiro exigia da Petrobras como o único operador até então e, também atualmente dos futuros operadores, o desenvolvimento de inovações em termos de logística, processos, equipamentos e materiais para fazer frente às condições inusitadas, como as grandes espessuras das lâminas de água envolvidas, as grandes distâncias existentes entre os campos de produção e a costa brasileira, além das grandes profundidades a serem perfuradas a partir do assoalho marinho.

O suprimento de petróleo do Pré-sal brasileiro no mercado internacional está atualmente inserido em um contexto de baixa cotação da commodity e de escassas descobertas relevantes de novos reservatórios. Em termos de fornecimento futuro de petróleo ao mercado internacional, a produção da Bacia de Santos, se posiciona de forma estratégica no segmento offshore em virtude do declínio nos últimos anos da produção das duas principais regiões produtoras de hidrocarbonetos offshore do planeta; Golfo do México e Mar do Norte (British Petroleum, 2017).

A Bacia de Santos deverá ser um dos principais responsáveis pelo aumento da oferta de petróleo no mercado internacional na próxima década, ao mesmo tempo, em que impactará a produção nacional, fazendo com que o Brasil tenha uma posição ainda mais relevante no cenário internacional (FIGURA 11).

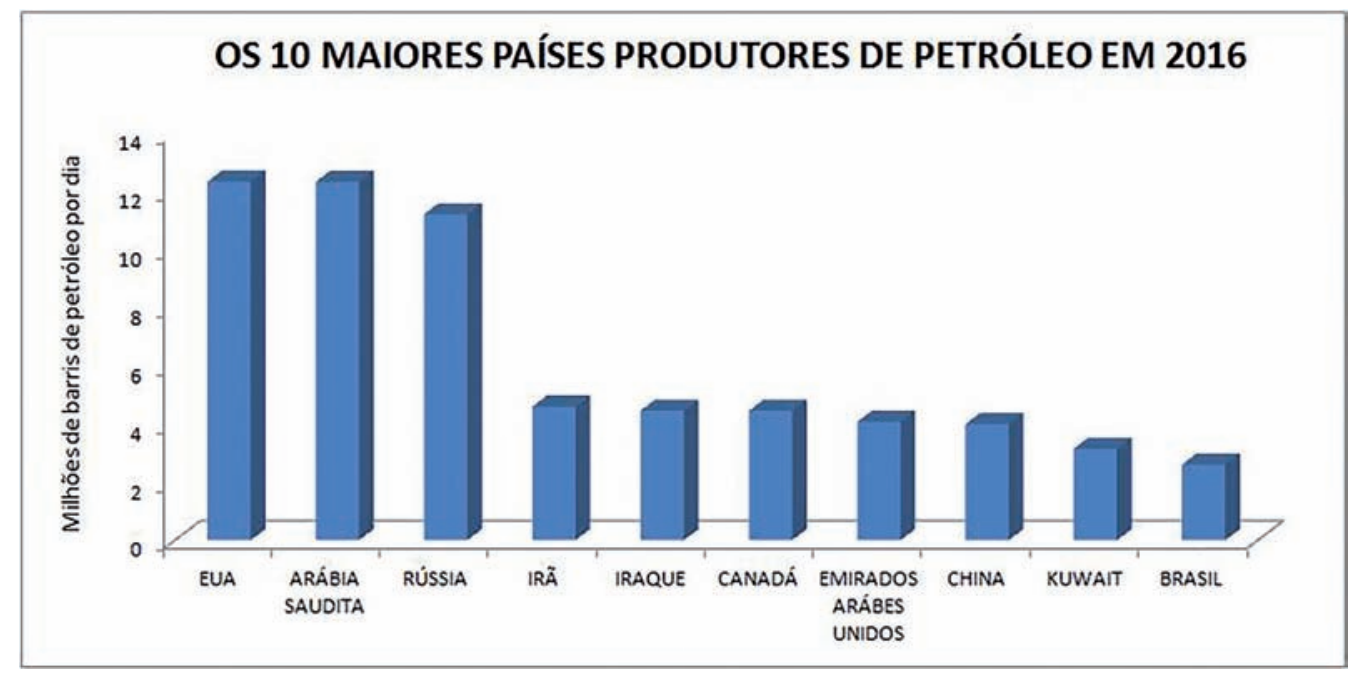

FIGURA 11. Os 10 maiores países produtores de petróleo em 2016. Modificado de: British Petroleum (2017).

Este potencial de incremento na oferta global da commodity atrai as atenções das principais companhias de petróleo do mundo que em um cenário de reduzidas reposições das reservas de hidrocarbonetos por fontes convencionais, vislumbram no acesso aos reservatórios do Pré-sal brasileiro a possibilidade da continuidade de parte de suas operações.

Embora haja um expressivo volume de petróleo e gás natural no Pré-sal, a redução do custo de produção torna-se vital para a viabilidade dos investimentos em Exploração e Produção na Bacia de Santos, sobretudo, em um período de manutenção da baixa cotação do barril de petróleo no mercado internacional. Neste quesito, o custo de produção tende a cair em virtude da entrada de novas plataformas de produção e da conexão de mais poços produtores junto às unidades em operação, além dos investimentos em infraestrutura de produção que já foram realizados.

Embora os volumes das reservas de petróleo e gás natural na Bacia de Santos não estejam quantificados em sua totalidade, Sauer e Rodrigues (2016) estimaram a existência de reservas recuperáveis variando de 42 a 
83,8 bilhões de barris de óleo equivalente (boe) de uma reserva total de 167 bilhões barris.

Outros fatores importantes que demonstram a posição estratégica do Pré-sal brasileiro, sobretudo a Bacia de Santos, no mercado internacional:

(i) Produção acumulada de 1 bilhão de barris de petróleo até dezembro de 2016.

(ii) Sucesso nas perfurações na área do Pré-sal da Bacia de Santos ser superior a média mundial.

(iii) Excelente vazão dos poços produtores.

(iv) Qualidade da maior parte do óleo ser leve $\left(\geq 31^{\circ}\right.$ API).

(v) Média do custo de produção do barril de petróleo ser inferior a 7 US\$.

O êxito da Petrobras na explotação dos reservatórios no Pré-sal na Bacia de Santos, atraiu as atenções da indústria mundial do petróleo, sobretudo das companhias internacionais concorrentes da Petrobras que passaram a analisar medidas que pudessem viabilizar o acesso aos reservatórios do Pré-sal brasileiro na Bacia de Santos.

As seis ações descritas a seguir demonstram a execução do planejamento das petroleiras internacionais para expandir suas atividades de exploração e produção nos reservatórios do Pré-sal brasileiro, principalmente na Bacia de Santos, ao mesmo tempo, em que a Petrobras reduz a sua participação nas atividades de exploração e produção de petróleo e gás natural no Pré-sal brasileiro.

Em 2015 a Royal Dutch Shell adquiriu por 52 bilhões de dólares o BG Group (detentora de participação em blocos de exploração e produção na Bacia de Santos), que nas palavras do Presidente da Royal Dutch Shell - Ben Van Beurden - sobre a qualidade dos ativos do Pré-sal brasileiro adquiridos com a fusão: "Estes ainda são fundamentalmente os melhores recursos em águas profundas disponíveis no planeta. E isso não vai mudar" (Paul, 2016).

A substituição em maio de 2016 da Presidente do Brasil, Dilma Roussef, pelo vice-presidente Michel Temer, este em completa consonância com os anseios das companhias internacionais.

Inicialmente a Petrobras vendeu a sua participação de $66 \%$ no Campo de Carcará no Pré-sal da Bacia de Santos (Petrobras, 2016a), justamente para uma concorrente, a Statoil, em julho de 2016.

Em outubro de 2016, o Congresso Nacional aprovou o fim da obrigatoriedade da Petrobras como a única operadora de todos os campos produtores de hidrocarbonetos no Pré-sal brasileiro (Brasil, 2016).

Em dezembro de 2016, a Petrobras reduziu a sua presença na Bacia de Santos com a venda de 22,5\% de sua participação nos campos de Sururu, Berbigão e Atapu, além de 35\% no Campo de Lapa (Petrobras, 2016b), para a sua concorrente internacional, a francesa Total.

Em outubro de 2017, a ANP realizou a $2^{\circ}$ e $3^{\circ}$ rodadas de partilha da produção nos blocos para a exploração e produção no Pré-sal brasileiro, desta forma, completou a última etapa do planejamento das principais companhias internacionais do petróleo para expandir suas atividades no Pré-sal brasileiro, nos exemplos da Royal Dutch Shell, Statoil, Total, Repsol-Sinopec, CNOOC e Petrogal, além do início das atividades de exploração e produção nos reservatórios abaixo da sequência evaporítica da Exxon Mobil e da British Petroleum (TABELA 2).

TABELA 2. Empresas estrangeiras vencedoras dos blocos para a exploração e produção na área do Pré-sal na Bacia de Santos nas $2^{\circ}$ e $3^{\circ}$ rodadas. Modificado de: ANP $(2017 \mathrm{~d})$.

\begin{tabular}{cccc}
\hline \multicolumn{4}{c}{ Rodadas de partilha de produção no pré-sal } \\
\hline & $\mathbf{2}^{\circ}$ Rodada & \multicolumn{2}{c}{$\mathbf{3}^{\circ}$ Rodada } \\
\hline Companhia & País de origem & Companhia & País de origem \\
\hline ExxonMobil & Estados Unidos & British Petroleum & Reino Unido \\
Petrogal & Portugal & CNODC & China \\
Repsol Sinopec & Espanha & CNOOC & China \\
Royal Dutch Shell & Reino Unido/Holanda & ExxonMobil & Estados Unidos \\
Statoil & Noruega & Qatar Petroleum & Catar \\
Total & Franca & Royal Dutch Shell & Reino Unido/Holanda \\
& & Statoil & Noruega
\end{tabular}




\section{CONCLUSÕES}

O conhecimento geológico acumulado sobre as bacias sedimentares da margem leste brasileira desde a perfuração do primeiro poço no final dos anos 1960 na Bacia do Espírito Santo foi o fator primordial para a viabilização da explotação dos reservatórios de hidrocarbonetos do Pré-sal.

As reservas de petróleo e gás contidas no Pré-sal brasileiro apresentam reservas de grandes dimensões, embora não quantificadas na sua totalidade. Contudo, ultrapassará dezenas de bilhões de barris de óleo equivalente, levando-se em consideração apenas as descobertas anunciadas pela Petrobras na Bacia de Santos, que posicionou o país entre as principais reservas de hidrocarbonetos do planeta.

O volume, vazão e a qualidade do óleo encontrados nos reservatórios do Pré-sal, possibilitam à Petrobras obter significativa redução do custo de produção e consequentemente uma competitividade em comparação aos concorrentes internacionais, em um momento de comercialização do barril de petróleo no mercado internacional em torno dos US\$ 70.

Por meio deste estudo é possível visualizar a mudança da condição de alvo exploratório da Bacia de Santos, que perdurou até o início da década passada, para a de principal produtora de hidrocarbonetos do país em setembro de 2017.

Da mesma forma, que principalmente o potencial do volume das reservas e da produção da Bacia de Santos foram responsáveis pela mudança na legislação para a exploração e produção de hidrocarbonetos na área do Pré-sal brasileiro, o fim da exclusividade da Petrobras como operadora única dos campos do Présal brasileiro ocorreu em virtude do interesse das grandes companhias internacionais em expandir a exploração e produção na Bacia de Santos, tendo em vista que atualmente a bacia representa $45 \%$ do total de petróleo e gás natural produzido no país e, continuará apresentando um forte crescimento na produção nos próximos anos.

A Petrobras como a única operadora nos campos produtores do Pré-sal brasileiro, permitiria ao país controlar o ritmo do aumento da produção de hidrocarbonetos, especialmente na Bacia de Santos, de acordo com as variações da cotação do barril de petróleo no mercado internacional.
A Petrobras deveria destinar a maior parte dos seus investimentos nas atividades de exploração e produção de hidrocarbonetos no país na Bacia de Santos, justamente no momento atual em que o mercado internacional apresenta a manutenção da baixa cotação do barril de petróleo.

O governo federal poderia deixar a cargo da Petrobras o planejamento da expansão da produção de hidrocarbonetos na Bacia de Santos, enquanto incentivasse os investimentos das companhias internacionais nas outras dezenas de bacias sedimentares onshore e offshore do país.

\section{AGRADECIMENTOS}

Os autores agradecem a leitura crítica desse texto pelo geólogo Prof. Gilmar Vital Bueno da Universidade Federal Fluminense (UFF, ex-Petrobras), assim como a Petrobras, pela bolsa de doutorado concedida ao primeiro autor. Esse texto integra o volume de doutoramento, ora em andamento.

\section{REFERÊNCIAS}

ANP. (2010). Sumário Executivo Externo do Campo de Mexilhão. Agência Nacional do Petróleo, Gás Natural e Biocombustíveis. Acesso em 11 de outubro de 2015. http://www.anp.gov.br/?dw=889.

ANP. (2012). Sumário Executivo do Campo de Atlanta. Agência Nacional do Petróleo, Gás Natural e Biocombustíveis. Acesso em 11 de outubro de 2015. http://webcache.googleusercontent.com/ search?q=cache:4MambTySMuQJ:www.anp.gov. br $/ \% 3 F d w \% 3 D 63585+\& c d=1 \&$ hl=en\&ct=clnk\&g $1=B R$.

ANP. (2013). Sumário Executivo do Campo de Oliva. Agência Nacional do Petróleo, Gás Natural e Biocombustíveis. Acesso em 11 de outubro de 2015. http://webcache.googleusercontent.com/ search?q=cache:zJbeRd_-RbAJ:www.anp.gov.br $1 \% 3 \mathrm{Fdw} \% 3 \mathrm{D} 19280+\& \mathrm{~cd}=1 \& \mathrm{hl}=\mathrm{en} \& \mathrm{ct}=\mathrm{clnk} \& \mathrm{gl}$ $=$ br.

ANP. (2015a). Banco de Dados de Exploração e Produção - BDEP. Agência Nacional do Petróleo, Gás Natural e Biocombustíveis. Acesso em 11 
de outubro de 2015. http://www.anp.gov.br/? $\mathrm{pg}=75852 \& \mathrm{~m}=\& \mathrm{t} 1=\& \mathrm{t} 2=\& \mathrm{t} 3=\& \mathrm{t} 4=\& \mathrm{ar}=\&$ $\mathrm{ps}=\& 1445835417554$.

ANP. (2015b). Boletim Mensal da Produção de Petróleo e Gás Natural. Agência Nacional do Petróleo, Gás Natural e Biocombustíveis. Acesso em 14 de fevereiro de 2016. http://www.anp.gov.br/ publicacoes/boletins-anp/2395-boletim-mensal-daproducao-de-petroleo-e-gas-natural.

ANP. (2015c). Petróleo e Estado. Rio de Janeiro: Agência Nacional do Petróleo, Gás Natural e Biocombustíveis.

ANP. (2015d). Plano de Desenvolvimento do Campo de Baúna. Agência Nacional do Petróleo, Gás Natural e Biocombustíveis. Acesso em 11 de outubro de 2015. http://www.anp.gov.br/?dw=75069.

ANP. (2015e). Plano de Desenvolvimento do Campo de Lagosta. Agência Nacional do Petróleo, Gás Natural e Biocombustíveis. Acesso em 11 de outubro de 2015. http://www.anp.gov.br/?dw=75745.

ANP.(2017a).AnuárioEstatístico2017.AgênciaNacional do Petróleo, Gás Natural e Biocombustíveis. Acesso em 01 de novembro de 2017. http://www.anp.gov. br/wwwanp/publicacoes/anuario-estatistico/3819anuario-estatistico-2017.

ANP. (2017b). Boletim Mensal da Produção de Petróleo e Gás Natural. Agência Nacional do Petróleo, Gás Natural e Biocombustíveis. Acesso em 01 de novembro de 2017. http://www.anp.gov.br/ wwwanp/publicacoes/boletins-anp/2395-boletimmensal-da-producao-de-petroleo-e-gas-natural.

ANP. (2017c). Dados de E\&P. Agência Nacional do Petróleo, Gás Natural e Biocombustíveis. Acesso em 15 de outubro de 2017. http://www.anp.gov. br/wwwanp/exploracao-e-producao-de-oleo-e-gas/ gestao-de-contratos-de-e-p/dados-de-e-p.

ANP. (2017d). Rodadas do pré-sal consolidam retomada do setor de petróleo e gás no Brasil. Agência Nacional do Petróleo, Gás Natural e Biocombustíveis. Acesso em 30 de outubro de 2017. http://www.anp.gov.br/.

Aquino, G.S., e Lana, M.C. (1990). Exploração na Bacia de Sergipe-Alagoas: o "estado da arte". Boletim de Geociências da Petrobras, 4(1), 3-11.
Arai, M. (2009). Paleogeografia do Atlântico Sul no Aptiano: um novo modelo a partir de dados micropaleontológicos recentes. Boletim de Geociências da Petrobras, 17(2), 331-351.

Arai, M. (2014). Aptian/Albian (Early Cretaceous) paleogeography of the South Atlantic: a paleontological perspective. Brazilian Journal of Geology, 44(2), 339-350. doi: 10.5327/Z23174889201400020012.

Assine, M.L., Corrêa, F.S., e Chang, H.K. (2008). Migração de depocentros na Bacia de Santos: importância na exploração de hidrocarbonetos. Revista Brasileira de Geociências, $38(2$ suplemento), 111-127. doi: 10.25249/0375$7536.2008382 \mathrm{~S} 111127$.

Azevedo, R.L.M. (2004). Paleoceanografia e a evolução do Atlântico Sul no Albiano. Boletim de Geociências da Petrobras, 12(2), 231-249.

Biassusi, A.S., Maciel, A.A., e Carvalho, R.S. (1990). Bacia do Espírito Santo: o "estado da arte" da exploração. Boletim de Geociências da Petrobras, 4(11), 13-19.

Brasil. (2016). Projeto de Lei 4567/16. Acesso em 21 de setembro de 2017. http://www2.camara.leg. br/camaranoticias/noticias/ECONOMIA/517342CAMARA-APROVA-FIM-DA-PARTICIPACAOOBRIGATORIA-DA-PETROBRAS-NO-PRESAL.html.

British Petroleum. (2017). BP Statistical Review of World Energy. Acesso em 15 de outubro de 2017. https://www.bp.com/en/global/corporate/energyeconomics/statistical-review-of-world-energy.html.

Bueno, G.V. (2004). Diacronismo de eventos no rifte Sul-Atlântico. Boletim de Geociências da Petrobras, 12(2), 203-229.

Caldas, M.F. (2007). Reconstituição cinemática e tectono-sedimentação associada a Domos salinos nas águas profundas da Bacia de Santos, Brasil. Dissertação de Mestrado. Universidade Federal do Rio de Janeiro, Rio de Janeiro, Brasil.

Chang, H.K., Assine, M.L., Corrêa, F.S., Tinen, J.S., Vidal,A.C., e Koike, L. (2008). Sistemas petrolíferos e modelos de acumulação de hidrocarbonetos na Bacia de Santos. Revista Brasileira de Geociências, 
38 (2 - suplemento), 29-46. doi: 10.25249/0375$7536.2008382 \mathrm{~S} 2946$.

CPRM. (2013). Projeto Batimetria. Serviço Geológico do Brasil. Acesso em 2 de dezembro de 2015. http:// www.cprm.gov.br/publique/Geologia/GeologiaMarinha/Projeto-Batimetria-3224.html.

Dias, J.L. (2008). Estratigrafia e sedimentação dos evaporitos neo-aptianos na margem leste brasileira. In: W.U. Mohriak, P. Szatmari, S. Anjos (Orgs.). Sal: Geologia e Tectônica. Exemplos nas Bacias Brasileiras (pp. 223-231). São Paulo: Beca Edições.

Dias-Brito, D. (1995). The South Atlantic Albian carbonates: their organogenic content and paleogeographic significance. I Workshop sobre paleoceanografia com ênfase em micropaleontologia e estratigrafia. Gramado, Brasil.

Estrella, G.O. (2014). Pré-Sal e Desenvolvimento Nacional: Oportunidades/Ameaças Estratégicas. Os Desafios do Pré-Sal: Riscos e Oportunidades para o País. Campinas, Brasil.

Filho, T.A., Mizusaki, A.M.P., e Antonioli, L. (2008). Magmatismo nas bacias sedimentares brasileiras e sua influência na geologia do petróleo. Revista Brasileira de Geociências, 38 (2 - suplemento), 128137. doi: 10.25249/0375-7536.2008382S128137.

Gamboa, L.A.P., Machado, M.A.P., Silveira, D.P., Freitas, J.T.R., e Silva, S.R.P. (2008). Evaporitos estratificados no Atlântico Sul. In: W.U. Mohriak, P. Szatmari, S. Anjos (Orgs.). Sal: Geologia e Tectônica. Exemplos nas Bacias Brasileiras (pp. 91-163). São Paulo: Beca Edições.

Garcia, S.F.M. (2012). Restauração estrutural da halotectônica na porção central da Bacia de Santos e implicações para os sistemas petrolíferos. Tese de Doutorado, Escola de Minas, Universidade Federal de Ouro Preto, Ouro Preto, Brasil.

GCA. (2010). Exame e Avaliação de Dez Descobertas e Prospectos Selecionadas no Play do Pré-sal em Águas Profundas na Bacia de Santos, Brasil. Gaffney, Cline \& Associates. Acesso em 19 de março de 2016. https://www.anp.gov.br/?dw=33422.
Mendonça, P.M.M., Spadini, A.R., e Milani, E.J. (2004). Exploração na Petrobras: 50 anos de sucesso. Boletim de Geociências da Petrobras, 12(1), 1-55.

Milani, E.J., Brandão, J.A.S.L., Zalán, P.V., e Gamboa, L.A.P. (2000). Petróleo na Margem Continental Brasileira: Geologia, Exploração, Resultados e Perspectivas. Revista Brasileira de Geofísica, 18(3), 351-396. doi: 10.1590/S0102261X2000000300012.

Milani, E.J., Rangel, H.D., Bueno, G.V., Stica, J.M., Winter, W.R., Caixeta J.M., e Neto O.C.P. (2007). Bacias sedimentares brasileiras: cartas estratigráficas. Boletim de Geociências da Petrobrás, 15(1), 1-572.

Mohriak, W.U. (2003). Bacias Sedimentares da Margem Continental Brasileira. In: L.A. Bizzi, C. Schobbenhaus, R.M. Vidotti, J.H. Gonçalves (eds.). Geologia, Tectônica e Recursos Minerais do Brasil (pp. 87-165). Serviço Geológico do Brasil - CPRM.

Mohriak, W.U. (2012). Bacias de Santos, Campos e Espírito Santo. In: Y. Hasui, C.D.R. Carneiro, F.F.M. Almeida, A. Bartorelli (Orgs.). Geologia do Brasil (pp. 481-496). São Paulo: Beca Edições.

Mohriak, W.U., e Szatmari, P. (2008). Tectônica de Sal. In: W.U. Mohriak, P. Szatmari, S.M.C. Anjos (Orgs.). Sal: Geologia e Tectônica. Exemplos nas Bacias Brasileiras (pp. 92-165). São Paulo: Beca Edições.

Morais J.M. (2013). Petróleo em águas profundas: uma história tecnológica da Petrobras na exploração e produção offshore. Brasilia: IPEA/PETROBRAS.

Moreira, J.L.P., Madeira, C.V., Gil, J.A., e Machado, M.A.P. (2007). Bacia de Santos. Boletim de Geociências da Petrobras, 15(2), 531-549.

Nogueira, M., e Gaier, R.V. (2017). Petrobras vê custo no pré-sal abaixo de US\$7/barril e atrasos em plataformas. Acesso em 06 de outubro de 2017. https://br.reuters.com/article/businessNews/ idBRKBN1AQ2PQ-OBRBS.

Paul, S. (2016). CEO da Shell diz que pode vender ativos para melhorar portfólio. Acesso em 30 de julho de 
2016. https://br.reuters.com/article/domesticNews/ idBRKCN0X918F.

Pereira, M.J., Barbosa, C.M., Agre, J., Gomes, J.B., Aranha, L.G.F., Saito, M., Ramos, M.A., Carvalho, M.D., Stamato, M., e Bagni, O. (1986). Estratigrafia da Bacia de Santos: análise das sequências, sistemas deposicionais e revisão litoestratigráfica. XXXIV Congresso Brasileiro de Geologia. Goiânia, Brasil.

Pereira, M.J., e Macedo, J.M. (1990). A Bacia de Santos: perspectivas de uma nova província petrolífera na plataforma continental sudeste brasileira. Boletim de Geociências da Petrobras, 4(1), 3-11.

Petrobras. (2005). Comercialidade de mais de três novos campos de Gás e Petróleo Leve. Acesso em 21 de setembro de 2017. http://www.investidorpetrobras. com.br/pt/comunicados-e-fatos-relevantes/ comercialidade-demais-tres-novos-campos-de-gase-petroleo-leve.

Petrobras. (2012). Declarações de Comercialidade de Petróleo Leve no Sul da Bacia de Santos. Acesso em 2 de dezembro de 2015. http://www. investidorpetrobras.com.br/pt/comunicados-efatos-relevantes/declaracoes-decomercialidade-depetroleo-leve-no-sul-da-bacia-de-santos.

Petrobras. (2016a). Negócio de US\$ 2,5 bi com Statoil reafirma nossa meta de parceria e desinvestimento. Acesso em 30 de julho de 2016. http://www. petrobras.com.br/fatos-e-dados/conselho-deadministracao-aprova-venda-departicipacao-nobloco-exploratorio-bm-s-8-para-statoil.htm.

Petrobras. (2016b). Plano de Negócios e Gestão 20172021. Acesso em 13 de dezembro de 2016. http:// www.petrobras.com.br/pt/quem-somos/estrategia/ plano-de-negocios-e-gestao/.

QGEP. (2018a). Campos de Atlanta e Oliva. Queiroz Galvão Exploração e Produção. Acesso em 12 de junho de 2018. http://qgep.infoinvest.com.br/static/ $\mathrm{ptb} /$ campos-de-atlanta-e-oliva.asp?idioma $=\mathrm{ptb}$.

QGEP. (2018b). Fato Relevante. Queiroz Galvão Exploração e Produção. Acesso em 12 de junho de 2018. http://www.qgep.com.br/ptb/2219/2018\%20 05\%2003\%20QGEP\%20Primeiro\%20oleo\%20 Atlanta\%20_PORT_VF.pdf.
Ramalho, A. (2018). Pré-sal abre espaço para produção fora da Petrobras. Acesso em 12 de junho de 2018. https://www.valor.com.br/empresas/5316241/presal-abre-espaco-para-producao-fora-dapetrobras.

Riccomini, C., Sant'Anna, L.G., e Tassinari, C.C.G. (2012). Pré-sal: geologia e exploração. Revista USP, 95, 33-42. doi: 10.11606/issn.2316-9036. v0i95p33-42.

Sauer, I.L. (2016). O pré-sal e a geopolítica e hegemonia do petróleo face às mudanças climáticas e à transição energética. In: Melfi, A.J., Campos, D.A., e Umberto, G.C (Orgs.). Recursos Minerais do Brasil: problemas e desafios (pp. 308-322). Academia Brasileira de Ciências.

Sauer, I.L., e Rodrigues, L.A. (2016). Pré-sal e Petrobras além dos discursos e mitos: disputas, riscos e desafios. Estudos Avançados, 30(88), 185-229. doi: $10.1590 / \mathrm{s} 0103-40142016.30880014$.

Souza, I.A. (2008). Falhas de transferência da porção norte da Bacia de Santos interpretadas a partir de dados sísmicos: sua influência na evolução e deformação da bacia. Tese de Doutorado, Instituto de Geociências e Ciências Exatas. Universidade Estadual Paulista, Câmpus de Rio Claro.

Souza, L.S., e Sgarbi, G.N.C. (2016). Bacia de Santos: de promissora a principal bacia produtora de hidrocarbonetos do Brasil. XLVIII Congresso Brasileiro de Geologia. Porto Alegre, Brasil.

Vieira, J. (2009). Nona Rodada de Licitações - Bacia de Santos. Acesso em 10 de outubro de 2015. http:// rodadas.anp.gov.br/arquivos/Round9/palestras/ Santos(portugues).pdf.

Zalán, P.V. (2012). Recursos Petrolíferos. In: Y. Hasui, C.D.R. Carneiro, F.F.M. Almeida, A. Bartorelli (Orgs.). Geologia do Brasil (pp. 833-837). São Paulo: Beca Ediçoes.

Leonardo Silveira de Souza

ORCID: 0000-0003-0582-9013

Geraldo Norberto Chaves Sgarbi

ORCID: 0000-0002-4543-3390

Trabalho recebido: 13 de novembro de 2017 . Trabalho aprovado: 1 de novembro de 2018 